\title{
Role of Hsp100/Clp Protease Complexes in Controlling the Regulation of Motility in Bacillus subtilis
}

\author{
Noël Molière ${ }^{1,2}$, Jörn Hoßmann ${ }^{2 \dagger}$, Heinrich Schäfer ${ }^{1}$ and Kürşad Turgay ${ }^{1,2 *}$ \\ ${ }^{1}$ Naturwissenschaftliche Fakultät, Institut für Mikrobiologie, Leibniz Universität Hannover, Hannover, Germany, ${ }^{2}$ Institut für \\ Biologie-Mikrobiologie, Freie Universität Berlin, Berlin, Germany
}

\section{OPEN ACCESS}

Edited by:

Marc Bramkamp,

Ludwig-Maximilians-University

Munich, Germany

Reviewed by:

Akos T. Kovacs,

Friedrich Schiller University of Jena,

Germany

Gert Bange,

LOEWE Center for Synthetic

Microbiology, Philipps-University

Marburg, Germany

${ }^{*}$ Correspondence:

Kürşad Turgay

turgay@ifmb.uni-hannover.de

${ }^{\dagger}$ Present Address:

Jörn Hoßmann,

Abteilung Molekulare

Infektionsbiologie, Helmholtz-Zentrum für Infektionsforschung,

Braunschweig, Germany

Specialty section:

This article was submitted to Microbial Physiology and Metabolism,

a section of the journal

Frontiers in Microbiology

Received: 17 December 2015 Accepted: 29 February 2016 Published: 16 March 2016

Citation:

Molière N, Hoßmann J, Schäfer H and Turgay K (2016) Role of Hsp100/Clp Protease Complexes in Controlling the Regulation of Motility in Bacillus subtilis. Front. Microbiol. 7:315. doi: 10.3389/fmicb.2016.00315
The Hsp100/Clp protease complexes of Bacillus subtilis ClpXP and ClpCP are involved in the control of many interconnected developmental and stress response regulatory networks, including competence, redox stress response, and motility. Here we analyzed the role of regulatory proteolysis by ClpXP and ClpCP in motility development. We have demonstrated that ClpXP acts on the regulation of motility by controlling the levels of the oxidative and heat stress regulator Spx. We obtained evidence that upon oxidative stress Spx not only induces the thiol stress response, but also transiently represses the transcription of flagellar genes. Furthermore, we observed that in addition to the known impact of ClpCP via the ComK/FlgM-dependent pathway, ClpCP also affects flagellar gene expression via modulating the activity and levels of the global regulator DegU-P. This adds another layer to the intricate involvement of Clp mediated regulatory proteolysis in different gene expression programs, which may allow to integrate and coordinate different signals for a better-adjusted response to the changing environment of $B$. subtilis cells.

Keywords: AAA+ proteins, regulatory proteolysis, ClpC, ClpX, ClpP, motility, Bacillus subtilis

\section{INTRODUCTION}

Hsp100/Clp proteases are compartmentalized protein degradation machines, which consist of a peptidase component (i.e., $\mathrm{ClpP}$ ) and an AAA+ ATPase (i.e., ClpC or ClpX). The peptidase subunits are arranged in a barrel-like double heptamer with the catalytic residues on the inside surface of the structure. Folded proteins are excluded from the catalytic sites because they are too large to fit through the opening of the pore and are thus protected from proteolysis. The AAA+ ATPases form a hexameric ring with a narrow pore, which associates with one or both sides of the peptidase barrel. Specific substrate proteins can be recognized by the N-terminal ATPase domain, often facilitated by adaptor proteins, and are unfolded and threaded through the pore by the AAA+ ATPase motor into the peptidase chamber, where they are degraded (Kirstein et al., 2009; Sauer and Baker, 2011).

Hsp100/Clp proteases participate in general and regulatory proteolysis in the bacterial cell. For example, the ClpCP complex in Bacillus subtilis acts in protein quality control by degradation of unfolded, misfolded or aggregated proteins, which accumulate under stress conditions such as heat shock (Krüger et al., 2000; Schlothauer et al., 2003). Interestingly, the same protein complex plays an important part in developmental processes by controlled degradation of transcription factors like the competence master regulator ComK (Turgay et al., 1998), the class III heat shock repressor CtsR 
(Derré et al., 1999; Krüger et al., 2001; Kirstein et al., 2007) and the anti-anti sigma factor SpoIIAB involved in sporulation (Pan et al., 2001). ClpCP may also play a role in the processing of SlrR, a newly identified regulator of biofilm formation (Chai et al., 2010). ClpE is homologous to ClpC, with the exception of the $\mathrm{N}$-terminal domain, which is homologous to the N-terminal domain of ClpX (Kirstein et al., 2009). ClpE appears to be important under severe heat shock conditions (Miethke et al., 2006).

An important regulatory substrate of the third B. subtilis Hsp100/Clp ClpXP protease is the thiol and oxidative stress transcription factor Spx (Nakano M. M. et al., 2002; Nakano S. et al., 2002). Under non-stress conditions, Spx is very efficiently turned over by ClpXP aided by the adaptor protein $\mathrm{YpbH}$, resulting in a low steady state concentration of the protein. When cells encounter oxidative or heat stress, $s p x$ transcription is upregulated (Helmann et al., 2001; Leelakriangsak et al., 2007). More importantly, the Spx protein is stabilized either by oxidative inactivation (Garg et al., 2009) or heat-mediated sequestration (Engman and von Wachenfeldt, 2015) of the adaptor protein $\mathrm{YjbH}$, leading to rapid accumulation of the active regulator (Zuber, 2009; Runde et al., 2014).

Spx is a transcriptional regulator, which forms a complex with the C-terminal domain of the RNA polymerase alpha subunit (alpha-CTD; Nakano et al., 2003b; Newberry et al., 2005). By enhancing RNA polymerase interaction with certain promoters, Spx can serve as an activator i.e., of genes encoding enzymes required to cope with thiol oxidative stress (Nakano et al., 2003a; Reyes and Zuber, 2008). Interestingly, Spx can act as a transcriptional repressor on another group of genes (Nakano et al., 2003a,b). According to the interference model, genes, which require an activator that binds to the RNA polymerase alphaCTD, are repressed because Spx competes with binding of the activators to the alpha-CTD (Nakano et al., 2003b; Zhang et al., 2006).

Another interesting process, in which Clp proteases appear to be involved, is the regulation of swimming motility in $B$. subtilis (Mukherjee and Kearns, 2014). Already during their initial characterization, $c l p P, c l p C$, and $c l p X$ mutant strains were reported to be non-motile (Rashid et al., 1996; Liu and Zuber, 1998; Msadek et al., 1998). However, the mechanisms, by which Clp proteases affect swimming motility, are currently only partially understood. Swimming or swarming bacterial cells are propelled by flagella, rotating filamentous helical structures, which are powered by an intra-membrane revolving motor. Gene regulation of flagellar assembly is a hierarchical process as described for Escherichia coli (Chevance and Hughes, 2008) and B. subtilis (Mukherjee and Kearns, 2014). No obvious flagellar master regulator such as FlhDC of $E$. coli has been identified in the B. subtilis genome, instead, the early flagellar genes (class II genes) are located in a single large fla/che operon (MárquezMagaña and Chamberlin, 1994). This operon is transcribed by the $\sigma^{\mathrm{A}}$ housekeeping sigma factor (Kearns and Losick, 2005) and is modulated by a number of transcription factors including DegU (Amati et al., 2004; Tsukahara and Ogura, 2008), CodY (Bergara et al., 2003), and SwrA (Kearns and Losick, 2005; Calvio et al., 2008). The sigD gene encoding the alternative sigma factor $\sigma^{\mathrm{D}}$ is positioned close to the $3^{\prime}$-end of the fla/cheoperon (Márquez-Magaña and Chamberlin, 1994; Cozy and Kearns, 2010). The class III or late flagellar genes include hag, which encodes flagellin, the major structural subunit of the flagellum. They are organized in separate transcriptional units controlled by $\sigma^{\mathrm{D}}$-dependent promoters (Márquez et al., 1990). $\sigma^{\mathrm{D}}$ is inhibited by its anti-sigma factor FlgM, which is an important morphogenetic checkpoint synchronizing gene expression with the assembly of the flagella (Mirel et al., 1994; Fredrick and Helmann, 1996; Bertero et al., 1999; Chevance and Hughes, 2008; Mukherjee and Kearns, 2014; Calvo and Kearns, 2015).

How could regulatory proteolysis by $\mathrm{Hsp} / 100 \mathrm{Clp}$ proteins act on motility development? Liu et al. could demonstrate that high ComK concentrations in $\operatorname{clp} C$ or mecA mutant cells result in a transcriptional read-through from comFA into flgM. This leads to over-production of FlgM, which inhibits $\sigma^{\mathrm{D}}$ and represses hag transcription and thus motility development (Liu and Zuber, 1998). However, another study has proposed a second comKindependent effect of a $c l p C$ mutant on motility (Rashid et al., 1996). In addition, the proteolysis substrates responsible for the effect of $c l p X$ on swimming motility are unknown to date.

Here, we analyzed the influence of regulatory proteolysis on swimming motility in detail and identified two transcriptional regulators, which inhibit swimming motility and are affected by Clp proteases. We found that $\mathrm{ClpCP}$, in addition to its control of the ComK mediated induction of FlgM expression (Liu and Zuber, 1998), also affects DegU P mediated inhibition of motility. Most interestingly, we observed that Spx, a proteolysis substrate of ClpXP, negatively regulates motility genes by an unknown, probably indirect mechanism. Thereby heat or oxidative stress signals sensed by ClpXP/Spx can result in a halt of motility in B. subtilis cells.

\section{MATERIALS AND METHODS}

\section{General Methods}

B. subtilis cells were cultured in Luria-Bertani (LB) medium (5 g/l yeast extract, $10 \mathrm{~g} / \mathrm{l}$ tryptone-peptone, $5 \mathrm{~g} / \mathrm{l} \mathrm{NaCl}$ ) at $37^{\circ} \mathrm{C}$ if not otherwise indicated. Overnight cultures were inoculated from freshly streaked colonies and grown in LB medium in the presence of appropriate antibiotics $(10 \mu \mathrm{g} / \mathrm{ml}$ chloramphenicol, $1 \mu \mathrm{g} / \mathrm{ml}$ erythromycin $+25 \mu \mathrm{g} / \mathrm{ml}$ lincomycin, $10 \mu \mathrm{g} / \mathrm{ml}$ kanamycin, $10 \mu \mathrm{g} / \mathrm{ml}$ tetracycline, or $100 \mu \mathrm{g} / \mathrm{ml}$ spectinomycin). Standard DNA manipulation was carried out as described previously (Sambrook et al., 2001). Protein concentrations were determined using the Bradford method (Bradford, 1976).

\section{Cloning}

Cloning was performed in E. coli XL-1 blue cells (Stratagene). Phusion High Fidelity DNA Polymerase (New England Biolabs) was used for PCR amplifications. Chromosomal DNA was used as a template. Restriction enzymes and T4 DNA Ligase were obtained from Fermentas. Primer sequences are listed in Table S3, plasmids are listed in Table S2. 
Plasmids pQE60-hag and pQE60-spx were constructed by amplification of the hag or spx genes using primers hagpQE60for and hagpQE60-rev or spxpQE60-for and spxpQE60-rev, respectively and cloning into plasmid pQE60 (Qiagen) using the NcoI and BamHI restriction sites. Plasmids pX-hag1 and pXhag4 were obtained by PCR amplification using primers hag1for and hag1-rev or hag4-for and hag4-rev, respectively, BamHI digestion and ligation into BamHI-digested pX plasmid. For plasmid pflgB152, the flgB152 promoter fragment was amplified using primers flgB152-for and flgB152-rev and cloned into plasmid pDG268 using the EcoRI and BamHI restriction sites. All plasmids were sequenced.

\section{Transformation/Strain Construction}

All strains used in this study are described in Table S1. Transformation with chromosomal DNA or plasmid DNA was performed by a standard method (Anagnostopoulos and Spizizen, 1961). Strains BNM421 and BNM426 were constructed by transformation of strain BNM126 ( $\Delta h a g$ ) with plasmids pX-hag1 or pX-hag4, respectively. BNM421 expresses the hag gene from the xylose-inducible $\mathrm{P}_{\mathrm{xyl}}$ promoter. In BNM426, a hag fragment, comprising 92 bases upstream and 32 bases downstream of the open reading frame, is under the control of $\mathrm{P}_{\mathrm{xyl}}$. Strain BNM426 complemented the swimming motility defect of the $\Delta$ hag mutant in the presence of xylose.

BNM109 was constructed using the technique of longflanking homology PCR as described previously (Wach, 1996) with the primers listed in Table S3. Strains BNM126 and BNM149 were constructed as described using plasmids pMADhag and pMADcomK as described previously (Arnaud et al., 2004; Blair et al., 2008). $\Delta c l p P, \Delta c l p C$, and $\Delta c l p X$ mutants were obtained by transformation of the recipient strains with chromosomal DNA from strains BNM103, BNM105, and BNM106, respectively. Strains BNM350 and BNM351 were constructed by transformation of strain BNM111 ( $\Delta s p x:: k a n)$ with plasmids pMMN521 or pSN56 (Nakano et al., 2003a), respectively. Strain BNM810 was acquired by transformation of the wild type strain with plasmid pSN56. The strains BNM1266, BNM1268, and BNM 1270 were constructed by transforming the B. subtilis168swrA ${ }^{+} \operatorname{deg} Q^{+}$(Gift of Nicola Stanley-Wall) with chromosomal DNA prepared from BNM103, 105, or 109 (Table S1).

To obtain strain BNM866, chromosomal DNA from strain $\mathrm{ABH} 282$, featuring a second copy of amyE at the $y w r K$ gene locus (Camp and Losick, 2009), was first transformed into the wild type strain 168, resulting in strain BNM860. BNM860 was then transformed with plasmid pSN56 (Nakano et al., 2003a) selecting for spectinomycin resistance and chloramphenicol sensitivity, which indicates integration of the $s p x^{\mathrm{DD}}$ construct into the $y w r K:: a m y E$ locus (BNM866). This strain produced Spx protein after isopropyl- $\beta$-D-thiogalactopyranoside (IPTG) induction, as verified by Western blot analysis (data not shown). Finally, to yield strains BNM878 and BNM1001, strain BNM866 was transformed with chromosomal DNA from strains BNM301 (amyE::PflgB-lacZ cat) or BNM328 (amyE::Phag-lacZ cat) selecting for chloramphenicol and spectinomycin resistance, indicating integration of the PflgB-lacZ or Phag-lacZ constructs at the original amyE locus, while the $\mathrm{spx}^{\mathrm{DD}}$ construct remains at the $y w r K$ :amyE locus. We confirmed by Western blot analysis that the resulting strains produce Spx protein in response to IPTG induction (data not shown).

\section{Pulse Chase Labeling and Immunoprecipitation}

Cells were grown in Belitsky minimal medium [50 mM Tris(hydroxymethyl)-amino methane (Tris) - $\mathrm{HCl} \mathrm{pH} \mathrm{7,5,} 15 \mathrm{mM}$ $\left(\mathrm{NH}_{4}\right)_{2} \mathrm{SO}_{4}, 8 \mathrm{mM} \mathrm{MgSO} 4,27 \mathrm{mM} \mathrm{KCl}, 7 \mathrm{mM}$ sodium citrate, $0.6 \mathrm{mM} \mathrm{KH}_{2} \mathrm{PO}_{4}, 2 \mathrm{mM} \mathrm{CaCl} 2,160 \mu \mathrm{g} / \mathrm{ml}$ L-tryptophan, $10 \mu \mathrm{M}$ $\mathrm{MnSO}_{4}, 1 \mu \mathrm{M} \mathrm{FeSO}, 4.5 \mathrm{mM}$ potassium glutamate, 0, 2\% glucose] to $\mathrm{OD}_{600} 0.7$ at $37^{\circ} \mathrm{C} .3 .5 \mathrm{ml}$ bacteria were removed and pulse labeled with $30 \mu \mathrm{Ci} \mathrm{L-}{ }^{35} \mathrm{~S}$-methionine for $10 \mathrm{~min}$ at $37^{\circ} \mathrm{C}$. Subsequently, cold L-methionine $(0.3 \mathrm{M})$ was added in 30-fold excess and samples were taken after the indicated incubation times and mixed with trichloroacetic acid (TCA) to a final concentration of $10 \% \mathrm{w} / \mathrm{v}$. TCA-precipitated samples were incubated on ice for $10 \mathrm{~min}$ and centrifuged for $15 \mathrm{~min}$ at $17,000 \mathrm{~g}$ and $4^{\circ} \mathrm{C}$. The pellets were washed twice in $1 \mathrm{ml}$ acetone, air-dried and resuspended in $20 \mu \mathrm{l}$ lysis buffer $(50 \mathrm{mM}$ Tris- $\mathrm{HCl} \mathrm{pH} 7.5$, $5 \mathrm{mM}$ EDTA, $1 \mathrm{mM}$ PMSF, $4 \mathrm{mg} / \mathrm{ml}$ lysozyme). The samples were boiled for $3 \mathrm{~min}$ at $95^{\circ} \mathrm{C}$. Two hundred and seventy microliters KI buffer (50 mM Tris-HCl pH 8, $150 \mathrm{mM} \mathrm{NaCl}, 0.5 \%$ Triton X-100, $1 \mathrm{mM}$ PMSF) was added and the samples were incubated on ice for $15 \mathrm{~min}$. Precipitate was separated by centrifugation for $15 \mathrm{~min}$ at $17,000 \mathrm{~g}$ at $4^{\circ} \mathrm{C}$. Hundred microliters of the supernatant were mixed with $2 \mu \mathrm{l}$ polyclonal anti-Hag antiserum and incubated over night at $4^{\circ} \mathrm{C}$ for immunoprecipitation. The next day, $8 \mu \mathrm{l}$ Protein A Magnabeads (Thermo Scientific) were added to the solution and mixed. The magnetic beads were washed twice in $200 \mu \mathrm{l} \mathrm{KI}$ buffer. Subsequently, the magnetic beads were resuspended in SDS sample buffer, boiled for $3 \mathrm{~min}$ at $95^{\circ} \mathrm{C}$ and applied to $12.5 \%$ SDS PAGE gels. Electrophoresis was performed at $25 \mathrm{~mA}$ per gel for $1 \mathrm{~h}$ and the gels were vacuum dried on Whatman paper for $2 \mathrm{~h}$ at $85^{\circ} \mathrm{C}$. The dried gels were placed on a phosphoimager screen for $24 \mathrm{~h}$ and screens were scanned using a Fla 2000 phosphoimager (Fujifilm, Japan).

\section{Motility Assay}

Overnight cultures grown in $\mathrm{LB}$ medium at $37^{\circ} \mathrm{C}$ were diluted to $\mathrm{OD}_{600} 2.0$ in fresh $\mathrm{LB}$ medium and $3 \mu \mathrm{l}$ were applied to tryptone agar plates containing $0.3 \% \mathrm{w} / \mathrm{v}$ agar (bacteriology grade, Carl Roth), $10 \mathrm{~g} / \mathrm{l}$ tryptone/peptone and $5 \mathrm{~g} / \mathrm{l} \mathrm{NaCl}$. The plates were incubated at $37^{\circ} \mathrm{C}$ for $8 \mathrm{~h}$. The growth behavior of all examined strains in liquid culture with the tryptone salt medium (utilized for the swimming plates) was comparable to growth in LB (data not shown).

\section{Protoplast Preparation}

Thirty milliliters of a growing B. subtilis culture were harvested by centrifugation and the pellets were washed twice in $1 \mathrm{ml} \mathrm{STM}$ (50 mM Tris- $\mathrm{HCl} \mathrm{pH} \mathrm{8,} 50 \mathrm{mM} \mathrm{NaCl}, 5 \mathrm{mM} \mathrm{MgCl}_{2}, 25 \% \mathrm{w} / \mathrm{v}$ sucrose). Subsequently, the pellets were re-suspended in $200 \mu \mathrm{l}$ STM buffer $+0.3 \mathrm{mg} / \mathrm{ml}$ lysozyme and incubated for $30 \mathrm{~min}$ at $37^{\circ} \mathrm{C}$ to obtain protoplasts. The protoplasts were washed twice in $1 \mathrm{ml} \mathrm{STM}$ and then lysed by resuspension in $200 \mu \mathrm{l}$ TM buffer 
without sucrose $(50 \mathrm{mM}$ Tris- $\mathrm{HCl} \mathrm{pH} 8,50 \mathrm{mM} \mathrm{NaCl}, 5 \mathrm{mM}$ $\mathrm{MgCl}_{2}$ ) containing $10 \mu \mathrm{g} / \mathrm{ml}$ DNase I and $10 \mu \mathrm{g} / \mathrm{ml}$ RNase A and incubated on ice for $30 \mathrm{~min}$. The lysate was centrifuged for $20 \mathrm{~min}$ at $17,000 \mathrm{~g}$ and $4{ }^{\circ} \mathrm{C}$ and the supernatant was transferred to a fresh tube. Total protein concentration was determined by the Bradford assay.

\section{Whole Cell Preparation}

One milliliter of a growing B. subtilis culture was harvested by centrifugation and the pellet was washed twice in $1 \mathrm{ml} \mathrm{STM}$ ( $50 \mathrm{mM}$ Tris- $\mathrm{HCl} \mathrm{pH} 8.0,50 \mathrm{mM} \mathrm{NaCl}, 5 \mathrm{mM} \mathrm{MgCl}_{2}, 25 \% \mathrm{w} / \mathrm{v}$ sucrose) $+0.3 \mathrm{mg} / \mathrm{ml}$ lysozyme and incubated for $5 \mathrm{~min}$ at $37^{\circ} \mathrm{C}$. 6x SDS sample buffer containing SDS and DTT was added and the samples were boiled at $95^{\circ} \mathrm{C}$ for $5 \mathrm{~min}$. The samples were centrifuged for $5 \mathrm{~min}$ at $17,000 \mathrm{~g}$ prior to SDS-PAGE separation.

\section{Western Blot Analysis}

Polyclonal antibodies against Hag and Spx were produced in rabbits by inoculation with purified $\mathrm{Hag}_{-} \mathrm{His}_{6}$ or $\mathrm{Spx}_{\mathrm{H}} \mathrm{His}_{6}$ (Pineda Antibody Services, Berlin, Germany). Rabbit-anti-Spx antibodies for initial experiments were kindly provided by Peter Zuber (University of Oregon). SigD antibodies from rabbit were kindly provided by John Helmann (Cornell University), rabbit-anti-CodY antibodies from Linc Sonenshein (Tufts University), and sheep-DegU antibodies from Nicola StanleyWall (University of Dundee).

Lysates from protoplasts were adjusted to equal concentration and $2.5-10 \mu \mathrm{g}$ per lane total protein were loaded onto 12.5 or $15 \%$ SDS-gels and separated by electrophoresis. Gels were blotted onto PVDF membranes in $20 \mathrm{mM}$ Tris- $\mathrm{HCl} \mathrm{pH} \mathrm{8.3,}$ $150 \mathrm{mM}$ glycine, $20 \% \mathrm{v} / \mathrm{v}$ methanol using a semi-dry blotting chamber. Blot membranes were blocked in TBS-M (50 mM Tris$\mathrm{HCl} \mathrm{pH} \mathrm{8.0,150} \mathrm{mM} \mathrm{NaCl,} \mathrm{5 \%} \mathrm{w/v} \mathrm{skim} \mathrm{milk)} \mathrm{and} \mathrm{incubated}$ with antisera diluted in TBS-M. Antisera were used at dilutions of 1:40,000 (anti-Hag), 1:5000 (anti-DegU, anti-SigD, anti-Spx), or 1:10,000 (anti-CodY). The blots were washed in TBS buffer (50 mM Tris- $\mathrm{HCl} \mathrm{pH} \mathrm{8.0,} 150 \mathrm{mM} \mathrm{NaCl}$ ) and incubated with secondary anti-rabbit (GE Healthcare) or anti-sheep (Sigma Aldrich) antibodies conjugated to alkaline phosphatase diluted 1:10,000 in TBS-M. The blot membranes were then equilibrated in AP buffer (100 mM Tris- $\mathrm{HCl} \mathrm{pH} 9.5,100 \mathrm{mM} \mathrm{NaCl}, 5 \mathrm{mM}$ $\mathrm{MgCl}_{2}$ ) and developed using ECF Western Blotting Reagent (GE Healthcare). The fluorescence signals were scanned using a Fla 2000 phosphoimager (Fujifilm, Japan).

\section{$\beta$-Galactosidase Assay}

One to five milliliters samples of a growing B. subtilis carrying a lac $Z$ fusion were collected and harvested by centrifugation for $5 \mathrm{~min}$ at $17,000 \mathrm{~g}$ and frozen at $-20^{\circ} \mathrm{C}$. For the $\beta$ galactosidase measurement, the cell pellets were thawed on ice and resuspended in $500 \mu \mathrm{l} \mathrm{Z}$ buffer $\left(100 \mathrm{mM} \mathrm{NaPO}_{4} \mathrm{pH} 7.0\right.$, $1 \mathrm{mM} \mathrm{MgSO}_{4}, 100 \mathrm{mM} \beta$-mercaptoethanol). Ten microliters toluene was added and the samples were thoroughly mixed and incubated on ice for $30 \mathrm{~min}$. For the assay, the samples were diluted 4-fold and transferred into a flat-bottom 96 well plate (final volume $200 \mu \mathrm{l}$ ). The reaction was started by addition of
$50 \mu \mathrm{l} \mathrm{ONPG} \mathrm{(4} \mathrm{mg/ml} \mathrm{in} \mathrm{Z} \mathrm{buffer)} \mathrm{using} \mathrm{an} \mathrm{8-channel} \mathrm{multi-}$ pipette (Eppendorf). Absorbance at $420 \mathrm{~nm}$ was measured every $60 \mathrm{~s}$ for $15 \mathrm{~min}$ at room temperature using a microplate reader (Tecan Instruments). The $\beta$-galactosidase activity (in Miller Units) was calculated from the linear slope of the absorbance at $420 \mathrm{~nm}$ over time correcting for the sample path length in the microplates. For comparison of $\beta$-galactosidase activities of strains exhibiting lag phases in growth (i.e., $\Delta c l p P$ and $\Delta c l p X$ mutants), the time axis was normalized to T0, the point of deviation from exponential growth.

\section{Spx ${ }^{\mathrm{DD}}$ Induction}

Strains BNM351 ( $\Delta s p x:: k a n$ amyE::P $\left.P_{H y}-s p x^{\mathrm{DD}}\right)$ and BNM350 $\left(\Delta s p x:: k a n\right.$ amyE::P $\left.P_{H y}-s p x\right)$ were grown in $\mathrm{LB}$ medium at $37^{\circ} \mathrm{C}$ to $\mathrm{OD}_{600}$ 0.3. Subsequently, the culture was split and expression of $s p x^{\mathrm{DD}}$ was induced by addition of $1 \mathrm{mM}$ IPTG to one half of the culture. Samples were withdrawn before addition of ITPG (0 min), 30 and $60 \mathrm{~min}$ thereafter and total RNA or total protein were prepared as described above for Northern or Western blot analysis.

\section{Thiol Oxidative Stress Experiments}

A growing culture was divided in early exponential phase and $1 \mathrm{mM}$ N,N, $\mathrm{N}^{\prime}, \mathrm{N}^{\prime}$-Tetramethyl-azodicarboxamide (diamide) was added to half of the culture to induce thiol oxidative stress. Samples were removed before addition of diamide at the indicated time points and $\beta$-galactosidase activity was determined. Cell lysates of the same samples were analyzed by SDS-PAGE and Western blot against Spx.

\section{Northern Blot Analysis}

All buffers used for RNA work were treated with $0.1 \%$ diethyl pyrocarbonate (DEPC) and autoclaved $\left(121^{\circ} \mathrm{C}, 20 \mathrm{~min}\right)$. RNA was prepared from $30 \mathrm{ml}$ B. subtilis cultures using the FastRNA Pro Blue kit (MP Biochemicals). Lysis was performed by shaking in a Retsch mill for $10 \mathrm{~min}$ at $1800 \mathrm{rpm}$. The RNA was digested with RNase free DNase I (Roche Applied Sciences) to remove contaminating DNA and subsequently purified by phenol-chloroform extraction and ethanol precipitation. The RNA concentration was determined by absorbance measurement at $260 \mathrm{~nm}$ using a NanoDrop spectrophotometer (Peqlab).

RNA samples were diluted in DEPC treated $\mathrm{H}_{2} \mathrm{O}$, mixed 1:1 with $2 x$ RNA sample buffer (60 mM MOPS-NaOH pH 7.0, $0.02 \% \mathrm{w} / \mathrm{v}$ Bromphenol blue, $75 \% \mathrm{v} / \mathrm{v}$ formamide, $3.33 \% \mathrm{w} / \mathrm{v}$ formaldehyde, $3 \% \mathrm{w} / \mathrm{v}$ Ficoll 70 ) and heated to $65^{\circ} \mathrm{C}$ for $10 \mathrm{~min}$. Ten microliters RNA Molecular Weight Marker III (Roche Applied Sciences) was applied to the gel as a size standard. The RNA was separated by electrophoresis on $1.2 \% \mathrm{w} / \mathrm{v}$ agarose gels in $40 \mathrm{mM}$ MOPS-NaOH pH 7.0, $5 \mathrm{mM}$ sodium acetate, $1 \mathrm{mM}$ EDTA, $0.1 \% \mathrm{w} / \mathrm{v}$ diethyl pyrocarbonate (DEPC) and $37 \% \mathrm{v} / \mathrm{v}$ formaldehyde for $2 \mathrm{~h}$ and $45 \mathrm{~min}$ at $80 \mathrm{~V}$. The gel was rinsed with 20x SSC (300 mM tri-sodium citrate pH 7.0, $3 \mathrm{M} \mathrm{NaCl}$, $0.1 \%$ DEPC) and vacuum blotted onto a positively charged nylon membrane (Roche Applied Sciences) in 10x SSC (150 mM trisodium citrate $\mathrm{pH} 7.0,1.5 \mathrm{M} \mathrm{NaCl}, 0.1 \% \mathrm{DEPC}$ ) for $1.5 \mathrm{~h}$ at $5 \mathrm{~mm} \mathrm{Hg}$ pressure. UV crosslinking was performed for $10 \mathrm{~min}$ at $328 \mathrm{~nm}$. Subsequently, the blot was stained in methylene blue 
solution $(0.02 \% \mathrm{w} / \mathrm{v}$ methylene blue, $300 \mathrm{mM}$ sodium acetate $\mathrm{pH}$ $5.5,0.1 \%$ DEPC) for 5 min to visualize ribosomal RNAs as a control for equal sample application and blotting. The membrane was destained in Bleaching buffer (0.2x SSC 1\% w/v SDS, $0.1 \%$ DEPC) and equilibrated in $2 \mathrm{x}$ SSC (30 mM tri-sodium citrate $\mathrm{pH}$ 7.0, 0.3 M NaCl, 0.1\% DEPC).

Digoxigenin (DIG) labeled DNA probes were prepared by PCR using PCR DIG labeling mix containing DIG-dUTP (Roche Applied Sciences). PCR was performed with Phusion High Fidelity DNA polymerase (New England Biolabs) using primers hag-probe-for and hag1-rev (see Table S3). A first round of PCR was performed with chromosomal DNA as a template in the absence of DIG labeling mix. The product of this reaction was used as a template for a second round of PCR in the presence of DIG labeling mix. The PCR products were purified by gel extraction using the ZymoClean ${ }^{\mathrm{TM}}$ Gel DNA recovery kit (Hiss Diagnostics) and eluted in $20 \mu \mathrm{l}$ DEPC treated $\mathrm{H}_{2} \mathrm{O}$. The probes were denatured for $5 \mathrm{~min}$ at $95^{\circ} \mathrm{C}$ and cooled rapidly on ice.

The nylon membrane was transferred to a hybridization glass tube and incubated with $20 \mathrm{ml}$ DIG Easy Hybridization solution (Roche Applied Sciences) for $1 \mathrm{~h}$ at $47^{\circ} \mathrm{C}$ with rotation in a hybridization oven. Twenty microliters DIG-labeled probe $(100 \mathrm{ng} / \mu \mathrm{l})$ was diluted in $20 \mathrm{ml}$ DIG Easy Hybridization solution and the membrane applied to the blot over night at $47^{\circ} \mathrm{C}$. The blot was washed twice with $20 \mathrm{ml}$ wash buffer $1(0.1 \% \mathrm{w} / \mathrm{v}$ SDS, $30 \mathrm{mM}$ tri-sodium citrate $\mathrm{pH} 7.0,0.3 \mathrm{M} \mathrm{NaCl}, 0.1 \% \mathrm{v} / \mathrm{v}$ DEPC) for $5 \mathrm{~min}$ at $47^{\circ} \mathrm{C}$ and twice with wash buffer $2(0.1 \% \mathrm{w} / \mathrm{v}$ SDS, $1.5 \mathrm{mM}$ tri-sodium citrate $\mathrm{pH} 7.0,15 \mathrm{mM} \mathrm{NaCl}, 0.1 \% \mathrm{v} / \mathrm{v}$ DEPC) for $30 \mathrm{~min}$ at $47^{\circ} \mathrm{C}$.

The blot membrane was blocked in Blocking buffer [100 mM maleic acid $\mathrm{pH} 7.5,150 \mathrm{mM} \mathrm{NaCl}, 1 \% \mathrm{w} / \mathrm{v}$ Blocking reagent (Roche Applied Sciences)] for $30 \mathrm{~min}$ at room temperature. Anti-digoxigenin antibodies conjugated to alkaline phosphatase (Roche Applied Sciences) were diluted 1:5000 in Blocking buffer and applied to the blot for $1.5 \mathrm{~h}$ at room temperature. Subsequently, the blot was washed twice for $15 \mathrm{~min}$ in Detection buffer 1 (100 mM maleic acid $\mathrm{pH} 7.5,150 \mathrm{mM} \mathrm{NaCl})$ and equilibrated in Detection buffer $2(100 \mathrm{mM}$ Tris- $\mathrm{HCl} \mathrm{pH} 9.5$, $100 \mathrm{mM} \mathrm{NaCl}, 5 \mathrm{mM} \mathrm{MgCl}_{2}$ ) for $2 \mathrm{~min}$. CDP Star solution (Roche Applied Sciences) was applied to the blot and the signal was detected using X-ray films.

\section{Electrophoretic Mobility Shift Assays}

DNA probes were produced by PCR amplification from chromosomal DNA using the primer sets flgB (-209 to -6$)$ for/flgB ( -209 to -6$)$-rev flgB ( -106 to 98$)$-for/flgB ( -106 to 98)-rev and flgB ( -1 to 203 )-for/flgB ( -1 to 203 )-rev (see Table S3) and purified by gel extraction.

Fifty nanograms of the DNA probes were mixed with purified Spx-His $_{6}$ at $1.25,2.5,5 \mu \mathrm{M}$ protein concentration in TSM buffer (10 mM Tris-HCl pH 7.5, 1 mM EDTA, 5\% v/v glycerol, $1 \mathrm{mM} \mathrm{MgCl} 2,10 \mathrm{mM} \mathrm{NaCl}$ ) in the presence of $1 \mu \mathrm{g}$ poly-d(IC; Roche Applied Sciences) and incubated for $20 \mathrm{~min}$ at room temperature. Subsequently, the samples were applied to $5 \% \mathrm{w} / \mathrm{v}$ polyacrylamide gels and electrophoresis was performed for $2 \mathrm{~h}$ at $80 \mathrm{~V}$ in TSM buffer. The gels were stained with ethidium bromide and bands were visualized by UV illumination.

\section{RESULTS}

\section{Clp Proteases Affect Regulation of Swimming Motility}

We examined the swimming motility of wild type and $c l p$ mutant $B$. subtilis cells and confirmed that $c l p P$ and $c l p C$ mutant strains exhibit a defect in swimming motility (Rashid et al., 1996; Liu and Zuber, 1998; Msadek et al., 1998). In addition we observed that a $c l p X$ mutant is non-motile, whereas a $c l p E$ mutant displayed similar motility to the wild type (Figure 1A).

We observed that the overall Hag protein level, the major Flagellin protein in $B$. subtilis, appears to be relatively stable, judging by in vivo by pulse chase experiments following immunoprecipitation in wild type $B$. subtilis cells (Figure S1). When we examined Hag levels in Clp mutant strains we observed very low Hag levels in $c l p C$ (Rashid et al., 1996) and no detectable Hag protein in $c l p X$ and $c l p P$ mutant strains (Figure 1B).

To investigate whether the observed effect of the mutants on Hag protein level is reflected in the mRNA levels of flagellar transcripts, we performed Northern blot experiments using a probe against the hag transcript. We observed that hag mRNA levels were strongly reduced in $\operatorname{clp} P, \operatorname{clp} C$, and $\operatorname{clp} X$ mutant strains (Figure S2). We noted an additional band of $\sim 500$ bases hybridizing with our probe in the $c l p C$ and hag mutants (Figure S2). This might be explained by an upregulation of the shorter $B$. subtilis yvzB transcript, which encodes a smaller homolog of Hag, in these mutants.

We conclude from these data that the absence of Clp proteases resulted in a swimming motility defect and strongly diminished Hag protein and transcript levels (Figure 1 and Figure S2), suggesting that ClpCP and ClpXP indirectly affect Hag protein

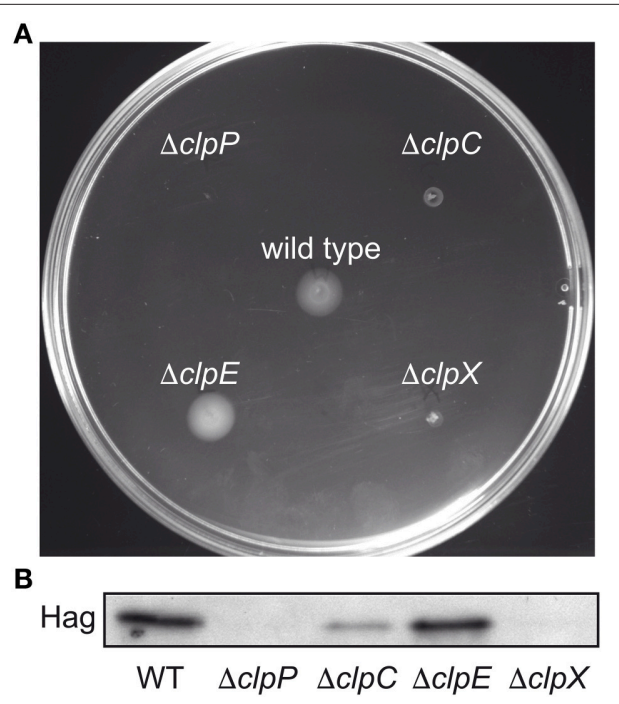

FIGURE 1 | Clp proteases affect swimming motility and Hag protein levels in B. subtilis. (A) Motility assay of $B$. subtilis wild type and $\Delta c / p P:: s p e c$ (BNM103), $\Delta c / p C::$ tet (BNM105), $\Delta c / p E:: s p e c$ (BNM106), and $\Delta c / p X:: k a n$ (BNM107) mutants on $0.3 \% \mathrm{w} / \mathrm{v}$ agar plates. (B) Cells of the indicated strains (as in $\mathbf{A}$ ) were grown to $\mathrm{OD}_{600} 1.0$ at $37^{\circ} \mathrm{C}$. Cell lysates were analyzed by SDS-PAGE and Western blotting using anti-Hag antibodies. 
levels, i.e., by regulatory proteolysis of transcriptional regulators controlling the synthesis of Hag.

\section{Clp Proteases Regulate Transcription from the flgB Promoter}

We first aimed to determine, which process in flagellar biogenesis is affected by the clp mutations. To this end, we performed reporter gene assays using transcriptional fusions of flagellar promoters to lac $Z$ to elucidate whether transcription initiation from these promoters is altered in clp mutant strains. One construct (PflgB-lacZ) contains the upstream sequence of the fla/che operon from residues -479 to +47 relative to the transcriptional start site of the $\sigma^{\mathrm{A}}$-dependent $f l g B$ promoter $\left(\mathrm{P}_{\mathrm{A}}\right)$ and is indicative of flagellar class II gene expression (Kearns and Losick, 2005). The minor $\sigma^{\mathrm{D}}$-dependent promoter, which does not influence flagellar gene expression (Kearns and Losick, $2005)$, is also present in this sequence $\left(\mathrm{P}_{\mathrm{D} 3}\right)$. To monitor the $\sigma^{\mathrm{D}}$ dependent class III genes we used a transcriptional lac $Z$ fusion to the hag promoter (Phag-lacZ) fusion (Kearns and Losick, 2005). All lacZ fusions were integrated into the ectopic amyE locus. We introduced $c l p$ mutations into these strains and determined $\beta$-galactosidase activities of samples along the growth curve.

In the wild type, both PflgB-lacZ and Phag-lacZ expression displayed the typical pattern of flagellar genes with a peak in post exponential phase (Mirel and Chamberlin, 1989; Figures 2A,B). Notably, in the $c l p P$ and $c l p X$ mutants, but not the $c l p C$ mutant, $P f \operatorname{lgB}$-lacZ activity was strongly reduced throughout growth (Figure 2A). The Phag-lacZ fusion was strongly down-regulated in the $\operatorname{clp} P, \operatorname{clpC}$, and $\operatorname{clp} X$ mutants (Figure 2B).

These results indicate that ClpXP affects transcription from the $f l g B$ promoter, whereas the lack of $\mathrm{ClpC}$ might affect hag promoter activity. However, as an additional control, we performed Western blots to determine the protein levels of the flagellar sigma factor $\sigma^{\mathrm{D}}$, which is encoded in the fla/che operon and directly activates transcription from the hag promoter. As expected, $c l p P$ and $c l p X$ mutants exhibited lower $\sigma^{D}$ protein levels, but the same was true for the $c l p C$ mutant (Figure 2C), even though $c l p C$ had no apparent effect on the activity of the tested PflgB-lacZ fusion (Figure 2A), suggesting that either $\operatorname{clpC}$ acts on $\sigma^{\mathrm{D}}$ post-transcriptionally or that additional elements near the fla/che promoter might be required for the observed down-regulation.

However, it was previously observed that the $\operatorname{fgB}$ promoter features two DegU binding sites, one located upstream of the promoter (BR1) and one downstream in the $f l g B$ coding region (BR2; Tsukahara and Ogura, 2008). The second BR2 element is not encoded in the $f \lg B$ promoter LacZ fusion we used so far. Therefore, we constructed a longer lac $Z$ fusion that included 17 additional bases upstream of the $f l g B$ start codon along with 88 bases of the flgB coding sequence (PflgB152-lacZ, see Materials and Methods and Figure 2D) including this additional DegU binding site (Tsukahara and Ogura, 2008). In the wild type background, this lac $Z$ fusion displayed a similar expression pattern as the PflgB-lac $Z$ construct, but peak expression was about three fold higher (Figure 2D). In addition, the $\operatorname{clpC}$ mutation had a strong negative effect on lacZ expression from this construct (Figure 2D). This suggests a possible role of DegU in the observed inhibition of swimming motility in the $c l p C$ mutant strain. In summary, our results suggest that transcription from the $f l g B$ promoter is strongly down-regulated in the $\operatorname{clp} P$, $c l p C$, and $c l p X$ mutants (Figures 2A,D), which results in lower protein levels of the flagellar sigma factor $\sigma^{\mathrm{D}}$ (Figure 2C). The lowered level of $\sigma^{\mathrm{D}}$ causes reduced transcription from the hag promoter (Figure 2B), lower Hag protein levels (Figure 1B) and reduced swimming motility (Figure 1A).

To further examine if the reduced Hag protein levels in $c l p$ mutants are solely a consequence of altered hag transcription, we uncoupled Hag production from $\sigma^{\mathrm{D}}$ regulation by placing a copy of hag downstream of the xylose-inducible $\mathrm{P}_{\mathrm{xyl}}$ promoter at the ectopic amyE locus of a hag deletion mutant (Figure S3, see Section Materials and Methods). Interestingly, Hag levels were completely restored to wild type levels in the $\operatorname{clp} C$ background, implying that $c l p C$ acts on motility genes upstream of the hag promoter. In contrast, Hag levels were only partially restored in the $c l p P$ and $c l p X$ mutants, suggesting an additional effect of $c l p P$ and $c l p X$ on hag transcript or Hag protein levels downstream of transcription initiation from the hag promoter (Figure S3).

\section{CIpC Influences Swimming Motility through ComK and DegU}

Controlled proteolytic degradation of a regulatory protein appears to be an important mechanism, by which Clp proteases can influence gene expression as demonstrated e.g., for the control of competence development (Kirstein et al., 2009; Battesti and Gottesman, 2013). Liu and Zuber previously described a pathway, by which $\mathrm{ClpCP}$ regulates swimming motility through ComK, which positively influences the transcription of FlgM. Briefly, ComK activates competence genes, among them comFA, which is located directly upstream of $f l g M$ on the chromosome. In the absence of $c l p C$, more FlgM is produced by transcriptional readthrough. FlgM inhibits $\sigma^{\mathrm{D}}$ activity, leading to decreased hag expression and reduced motility (Liu and Zuber, 1998).

To confirm that the reduced swimming motility of the $\operatorname{clp} C$ mutant is due to raised ComK levels, we tested the motility and Hag protein levels of the $\operatorname{clpC} \operatorname{comK}$ double mutant strain. As shown in Figure S4, the comK mutation partially suppressed the swimming motility and Hag production defect of the $\operatorname{clpC}$ mutant. These results indicate that part of the motility defect of a $\operatorname{clpC}$ mutant is due to higher levels of ComK and supports the read-through transcription of $f l g M$ as suggested by Liu and Zuber (Liu and Zuber, 1998). However, FlgM is unlikely to play a part in the down-regulation of $f l g B$ promoter activity because FlgM specifically inhibits $\sigma^{\mathrm{D}}$ (Caramori et al., 1996), whereas PflgB transcription is independent of $\sigma^{\mathrm{D}}$ (Kearns and Losick, 2005).

Therefore, we examined other known repressors of the fla/che operon. One candidate is DegU, which can act as a repressor of the fla/che operon in its phosphorylated form (Amati et al., 2004). In addition, the DNA element between positions +48 and +152 relative to the transcription start site of the $f l g B$ promoter, which is required for the $\operatorname{clp} C$ mediated down-regulation of fla/che transcription (Figure 2D), contains a DegU $\sim \mathrm{P}$ binding site 
A

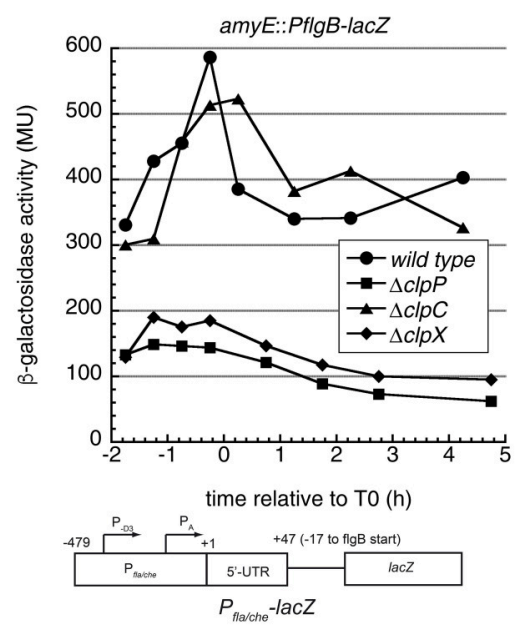

C

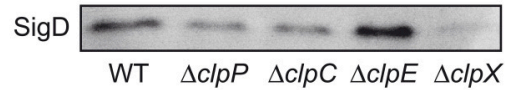

D
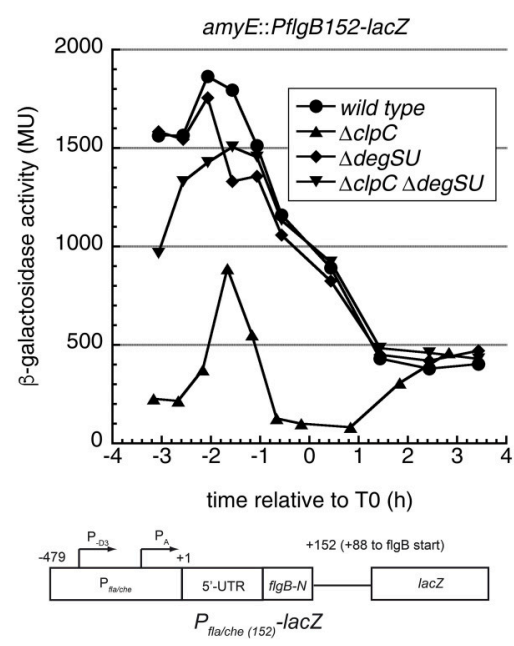

$\mathbf{F}$

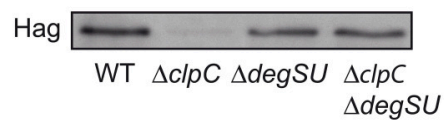

B
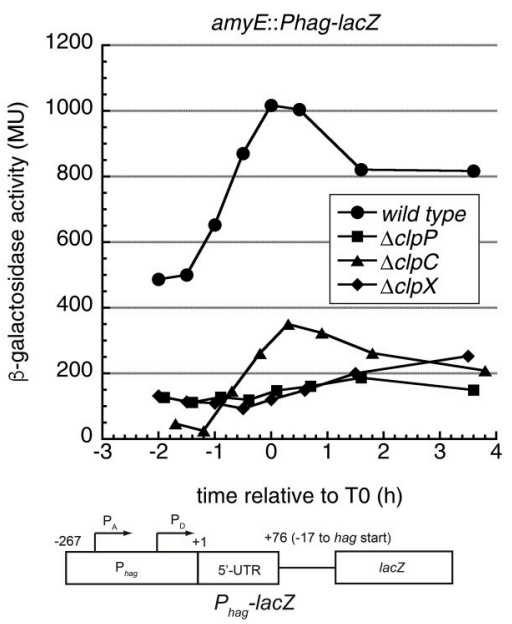

E

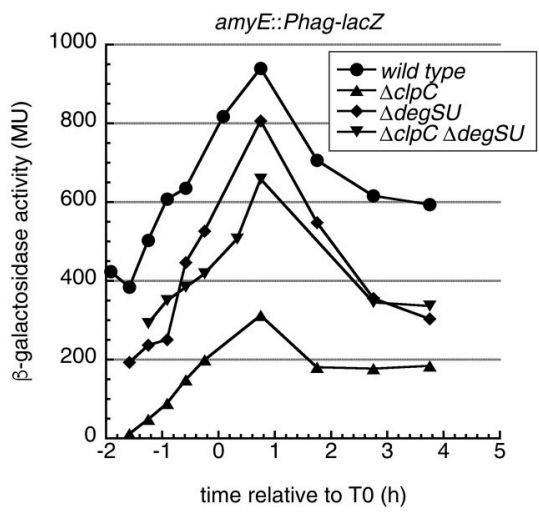

G

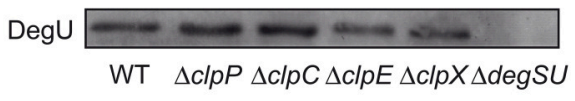

FIGURE 2 | Motility genes are down-regulated in B. subtilis clp mutant cells and the role of $\mathbf{c l p C}$ and degSU. (A) $\beta$-galactosidase assays of the indicated strains carrying a PflgB-lacZ fusion. Circles: wild type 168 (BNM301), squares: $\Delta c / p P:: s p e c$ (BNM302), triangles: $\Delta c / p C:: t e t$ (BNM303), diamonds: $\Delta c / p X:: k a n$ (BNM305). Representative data from at least two independent experiments are shown. A schematic drawing of the promoter-lacZ fusion is depicted at the bottom. (B) Same as (A) for the hag promoter lacZ fusion. Circles: wild type 168 (BNM328), squares: $\Delta c l p P:: s p e c$ (BNM329), triangles: $\Delta c / p C:: t e t$ (BNM330), diamonds: $\Delta c / p X:: k a n$ (BNM332). (C) Cells of strains wild type, BNM103 $(\Delta c / p P)$, BNM105 $(\Delta c / p C)$, BNM107 $(\Delta c / p X)$ were grown to OD 6001.0 at $37^{\circ} \mathrm{C}$. Cell lysates were analyzed by SDS-PAGE and Western blotting using anti-SigD (D) $\beta$-galactosidase assays of the indicated strains carrying a PflgB152-lacZ fusion Circles: wild type 168 (BNM346), triangles: $\Delta c / p C::$ tet (BNM347), diamonds: $\Delta$ degSU::spec (BNM348), inverted triangles: $\Delta c l p C::$ tet $\Delta$ degSU::spec (BNM349). Representative data from at least two experiments are shown. A schematic drawing of the promoter-lacZ fusion is depicted at the bottom. (E) Same as (D) for the hag promoter lacZ fusion. Circles: wild type (BNM328), triangles: $\triangle c l p C$ (BNM330), diamonds: $\triangle$ degSU (BNM333) and inverted triangles: $\Delta c / p C \Delta d e g S U$ (BNM338). (F) Cells of the wild type and strains BNM105 ( $\Delta c / p C)$, BNM138 ( $\Delta$ degSU), and BNM140 ( $\Delta$ clpC $\Delta$ degSU) were grown to OD 6001.0 at $37^{\circ} \mathrm{C}$. Cell lysates were analyzed by SDS-PAGE and Western blotting using anti-Hag antibodies. (G) Cells were grown at $37^{\circ} \mathrm{C}$ to TO (time of deviation from exponential growth) and cell lysates of the wild type and strains BNM103 $(\Delta c / p P)$, BNM105 ( $\Delta c / p C)$, BNM106 ( $\Delta c / p E)$, BNM107 ( $\Delta c / p X)$, and BNM138 $(\Delta d e g S U)$ were analyzed by SDS-PAGE followed by Western blotting using anti-DegU antibodies. 
(Tsukahara and Ogura, 2008) and DegU P has been described as a possible ClpCP substrate (Ogura and Tsukahara, 2010).

We tested whether DegU levels can be elevated in a $c l p C$ mutant. To this end we performed DegU Western blots in wild type and $c l p$ mutant strains at different time points during growth. Notably, only between $\mathrm{T}_{0}$ and $\mathrm{T}_{2}$, at a time when cells are motile and expressing flagellar genes, we detected mildly increased levels of DegU in the $c l p C$ and to a lesser extent in the $c l p P$ mutants compared to the wild type (Figure 2G and Figure S5).

In order to test whether $\operatorname{deg} U$ is responsible for the motility defect of the $c l p C$ mutant, we constructed a $c l p C \operatorname{degSU}$ double mutant and tested swimming motility, Hag protein levels and motility gene expression of this strain. In this mutant, $\operatorname{deg} U$ is deleted along with the $\operatorname{degS}$ gene, which encodes its cognate sensor kinase DegS. Indeed, the degSU mutation suppressed the swimming defect of the $c l p C$ mutant (Figure 3) and restored Hag production almost to wild type levels (Figure 2F), whereas mutation of degSU alone did not influence swimming and Hag concentration. Furthermore, $\beta$-galactosidase activity of the $f \lg B$ lac $Z$ and to a little lesser extent of the hag-lac $Z$ promoter reporter fusions was restored in the $c l p C$ degSU double mutant compared to the $\operatorname{clp} C$ mutant, but was significantly more similar to the wild type in the degSU mutant (Figures 2D,E). This suppression was specific to $c l p C$, as the $\operatorname{degSU}$ mutation did not suppress down-regulation of the hag-lacZ promoter fusion and swimming motility in the $c l p X$ mutant (Figure S6). These results suggest that ClpC negatively influences DegU repressor activity.

We observed a growth dependent mildly raised level of DegU in a $c l p C$ and to a lesser extent in a $c l p P$ mutant strain (Figure $\mathrm{S} 5$ ), which is consistent with the hypothesis that under specific conditions ClpC could inhibit or ClpCP could also degrade DegU-P (Ogura and Tsukahara, 2010) and that, in the absence of $c l p C$, active DegU-P can accumulate and thereby represses transcription from the $f \lg B$ promoter (Figure 2D).

\section{Influence of the Repressor Cody on Motility}

The repressor CodY, which can sense GTP and branched chain amino acids, has been reported to bind to the $\operatorname{flgB}$ and hag promoters (Bergara et al., 2003; Ababneh and Herman, 2015). However, it was also observed that a $\operatorname{cod} Y$ deletion did not influence motility and fla/che expression (Amati et al., 2004) and a recent study, investigating the genome wide CodY binding sites did not detect CodY binding sites for controlling the $\mathrm{flgB}$ promoter (Belitsky and Sonenshein, 2013).

We could only detect small differences in motility of a $\operatorname{cod} Y$ mutant strain compared to wild type cells (Figure S7B) and we could not detect differences in the levels of cellular CodY protein in $c l p C, c l p X, c l p E$, or $c l p P$ strains (Figure S7A). These results suggest that under our experimental conditions and in our strain background neither ClpCP nor ClpXP strongly influence motility via CodY.

\section{ClpXP Regulate Swimming Motility through SpX}

According to the data presented above, motility genes are strongly down-regulated in the $\operatorname{clp} X$ and $\operatorname{clp} P$ mutants.

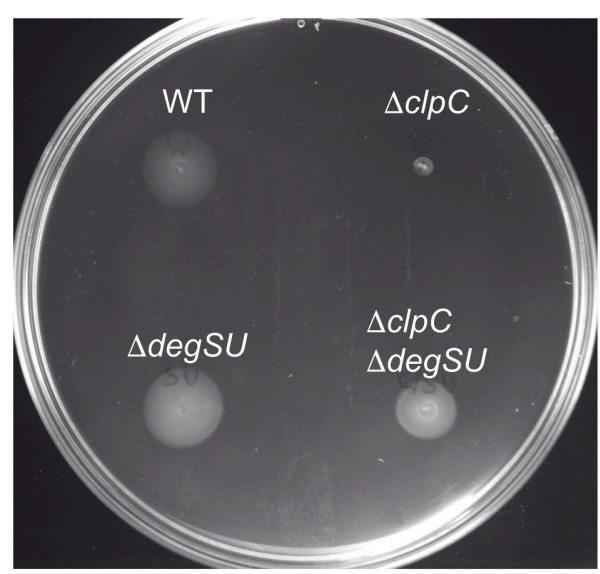

FIGURE 3 | A degSU mutation suppresses the swimming motility defect of a $\boldsymbol{B}$. subtilis clpC mutant strain. Motility assay of the wild type and strains BNM105 ( $\Delta$ clpC), BNM138 ( $\Delta$ degSU), and BNM140 ( $\Delta$ c/pC $\Delta$ degSU).

Interestingly, these mutants are phenotypically distinct from the $c l p C$ mutant: for example, the shorter PflgB-lacZ fusion was down-regulated in $c l p X$ and $c l p P$ mutants, but not in the $c l p C$ mutant. Furthermore, our data indicate that $c l p X$ and $c l p P$ act on swimming motility independently of $\operatorname{deg} U$ (Figure S6). Therefore, we assumed that distinct substrates of ClpCP and ClpXP regulate motility.

Both $c l p P$ and $c l p X$ mutants have a slow growth phenotype, which leads to frequent acquisition of second site suppressor mutants. We isolated such suppressor mutants, which could be easily identified by larger colony size on plates and loss of the characteristic lag phase during growth in liquid medium (Figure S8A). Interestingly, we noticed that this strain was only slightly less motile than the wild type (Figure $\mathrm{S} 8 \mathrm{~B}$ ) and produced wild type levels of Hag protein (Figure S8C). One well-characterized suppressor mutation of $c l p X$ and $c l p P$ mutants is a loss of function mutation in the spx gene, which relieves the detrimental effect of raised levels of the ClpXP substrate Spx (Nakano et al., 2001). We analyzed Spx levels by Western blot using polyclonal Spx antibodies and detected only very low levels of Spx in the wild type strain and no Spx in the $c l p P$ suppressor mutant, whereas Spx accumulated to high levels in a freshly transformed $c l p P$ mutant (Figure S8C). This strongly suggested that our isolated suppressor mutant of $c l p P$ is phenotypically similar to a $s p x$ mutant.

We therefore tested swimming motility and Hag levels in a clean $\operatorname{clp} X \operatorname{spx}$ double deletion mutant. Interestingly, the $\operatorname{spx}$ mutation resulted in increased motility on swim plates, whereas cellular Hag levels were similar to the wild type strain in this mutant (Figures 4A,B). Furthermore, the $s p x$ mutant suppressed the swimming motility defect of the $c l p X$ mutant and restored Hag production to wild type levels (Figures $4 A, B$ ). In addition, the activity of the PflgB-lacZ and Phag-lacZ fusions was partially restored in the $c l p X s p x$ double mutant (Figures 5A,B), suggesting that the $\operatorname{flg} B$ promoter is to a large extent regulated by $c l p X$ via $s p x$. The $s p x$ single mutant was significantly more similar to the wild type in these reporter gene assays (Figures $\mathbf{5 A , B}$ ). 
A

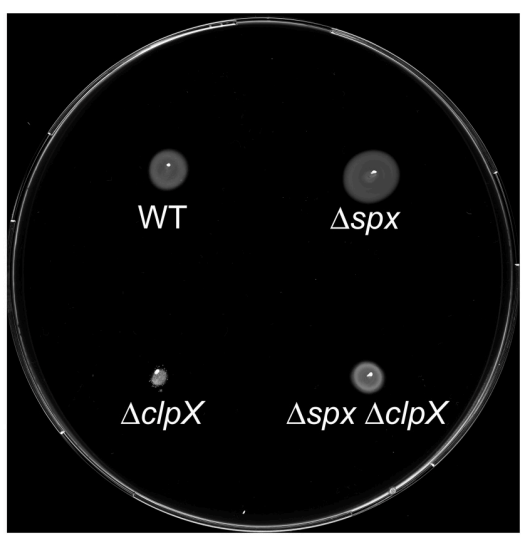

B Hag

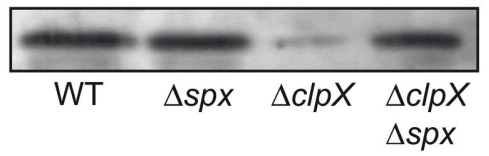

FIGURE 4 | spx suppresses the swimming motility defect of a $B$. subtilis clpX mutant strain. (A) Motility assay of the wild type and strains BNM107 ( $\Delta c / p X), B N M 111(\Delta s p x)$, and BNM112 ( $\Delta c / p X \Delta s p x)$. (B) Cells of the indicated strains (as in $\mathbf{A}$ ) were grown to $\mathrm{OD}_{600} 1.0$ at $37^{\circ} \mathrm{C}$. Cell lysates were analyzed by SDS-PAGE and Western blotting using anti-Hag antibodies.

Interestingly, we observed that the Hag levels were also restored in $\operatorname{clpX} \operatorname{spx}$ mutant in a strain with xylose-controlled hag expression (Figure S3D), implying that the observed additional posttranscriptional effect of $c l p X$ on hag is $s p x$-dependent.

\section{Spx Negatively Regulates Motility Genes}

These results indicate that the reduced swimming motility of the clpX mutant might be caused by the presence of Spx, which negatively regulates the $f l g B$ promoter. To test whether Spx is able to inhibit motility also in a $\operatorname{clp} X^{+}$background, we utilized a strain, in which a stabilized $\mathrm{Spx}$ variant $\left(\mathrm{Spx}{ }^{\mathrm{DD}}\right)$ that can no longer be degraded by ClpXP, is encoded at the amyE locus under the control of an IPTG-inducible promoter (Nakano et al., 2003a). Notably, this strain was no more motile in the presence of IPTG, while an additional induction of wild type Spx had no effect on motility (Figures 6A,B), indicating that a raised level of Spx negatively regulates swimming motility.

In order to elucidate whether transcription from the $f g B$ and hag promoters is regulated by $s p x^{\mathrm{DD}}$ induction, we inserted the PflgB-lacZ or Phag-lacZ reporter fusions at an additional ectopic locus $(y w r K)$ of a strain carrying an IPTG-inducible copy of $s p x^{\mathrm{DD}}$ at the $a m y E$ locus (see Materials and Methods). We grew these strains to early exponential phase, induced $s p x^{\mathrm{DD}}$ by addition of IPTG and determined $\beta$-galactosidase activity of these strains (Figures 6C,D).

The activity of both promoters was strongly repressed compared to the un-induced control for a period of $\sim 3 \mathrm{~h}$ after induction and subsequently increased (Figures 6C,D). As an additional control, we analyzed the hag mRNA levels by Northern blot analysis and Hag protein levels by Western blot analysis of a strain carrying an IPTG-inducible copy of $s p x^{\mathrm{DD}}$ at the amyE locus (Figure S9). The hag transcript level decreased below the detection limit of our Northern blot experiment after 30 min of $s p x^{\mathrm{DD}}$ induction Figure S9A). Hag protein levels also decreased after $s p x^{\mathrm{DD}}$ induction, however this effect was not as pronounced as for hag mRNA (Figure S9B), which is possibly due to the observed stability of Hag (Figure S1).

$\mathrm{YjbH}$ is an adapter protein, which specifically recognizes Spx and targets it for degradation by ClpXP. As an additional test to analyze the effect of increased Spx levels on motility, we assayed an $y j b H$ deletion mutant for swimming motility and Hag levels. Similar to the $c l p X$ mutant, the $y j b H$ mutant strain was unable to swim and displayed strongly decreased Hag levels. In contrast, an $s p x y j b H$ double mutant was highly motile and displayed wild type level of Hag protein (Figure S10).

Taken together, these data suggest that Spx acts as a negative regulator of swimming motility.

\section{Motility Genes Are Down-Regulated In Response to Thiol Oxidative Stress}

Spx is present at very low concentrations in growing, nonstressed cells due to regulatory proteolysis by ClpXP and repression of the $s p x$ gene. In response to oxidative stress, $s p x$ is transcriptionally de-repressed (Leelakriangsak et al., 2007) and Spx is stabilized (Zhang and Zuber, 2007; Garg et al., 2009).

Since our results suggest that Spx acts as a negative regulator of motility, it is conceivable that motility is repressed under conditions, when Spx accumulates in the cell, such as during thiol oxidative stress. To test this we subjected the $P$ flgB-lacZ and Phag-lacZ reporter strains to oxidative stress by addition of $1 \mathrm{mM}$ diamide, a strong inducer of Spx activity and collected samples for determination of $\beta$-galactosidase activity.

Whereas, the non-stressed control samples displayed a normal pattern of flagellar gene expression, PflgB-lacZ and Phag-lacZ activity strongly decreased for a period of $1-1.5 \mathrm{~h}$ after the application of oxidative stress (Figures 7A,B). Notably, Western blot analysis of the same samples with Spx-specific antibodies revealed that Spx protein was present in high amounts at the time points, at which flagellar gene expression was most strongly repressed (Figures 7A,B).

In summary, our data indicate that $\mathrm{Spx}$ acts as a negative regulator of the $f g B$ promoter, which also affects $\sigma^{\mathrm{D}}$ levels and thus transcription from the hag promoter.

\section{Spx Regulates Motility Indirectly on both flgB and hag Promoter}

Our results clearly demonstrate that a raised cellular level of Spx results in a repression of the $f l g B$ promoter. We already demonstrated that Spx does not act on this promoter via DegU (Figure S6). Furthermore, we tested whether the defect of swimming motility in a $c l p X$ mutant is suppressed by a $\operatorname{cod} Y$ mutation. Swimming motility, Hag protein levels as well as $f l g B$ promoter activity were not increased in the $\operatorname{clpX} \operatorname{cod} Y$ double mutant compared to the $c l p X$ single mutant (Figures S7B-E).

Interestingly, the hag promoter activity was increased especially at later time points in the double $\operatorname{cod} Y \operatorname{clp} X$ mutant 

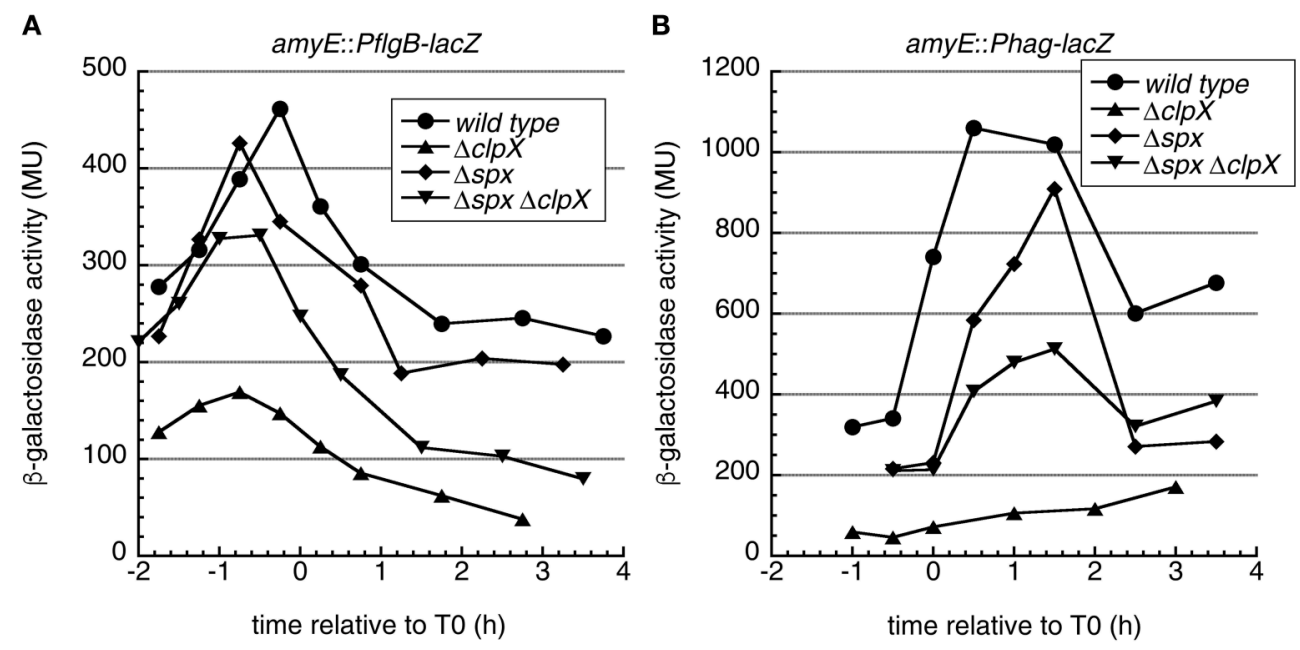

FIGURE 5 | clpX affects motility gene expression via spx. (A) $\beta$-galactosidase assays of the indicated strains carrying a PflgB-lacZ fusion. Circles: wild type 168 , triangles: $\Delta c l p X:: k a n$ (BNM305), diamonds: $\Delta$ spx::kan (BNM307), inverted triangles: $\Delta$ spx::kan $\Delta c l p X::$ spec (BNM308). Representative data from 2 to 3 experiments are shown. (B) Same as (A) for the hag promoter lacZ fusion. Circles: wild type 168, triangles: $\Delta c / p X:: k a n$ (BNM332), diamonds: $\Delta$ spx::kan (BNM334), inverted triangles: $\Delta$ spx::kan $\Delta c / p X:: s p e c(B N M 335)$.

strain. These data suggest that CodY might be somehow indirectly involved in the Spx dependent repression of the hag promoter in the $c l p X$ mutant. The results presented earlier in Figure S3 already suggested an influence of Spx on the hag promoter independent of its influence on the $\lg B$ promoter (Figure S3). However, Spx-mediated down-regulation of the $f l g B$ promoter appears to be mostly independent of $\operatorname{cod} Y$ under our experimental conditions and in our strain background (Figure S7).

To test whether Spx directly binds to the $f l g B$ promoter, we performed electrophoretic mobility shift assays using $f l g B$ promoter DNA fragments and purified Spx protein (see SectionMaterials and Methods). In accordance with previously published results on Spx (Nakano et al., 2010), we did not observe DNA binding of Spx to the PflgB promotor region (Figure S11), suggesting that $\mathrm{Spx}$ indirectly regulates $\mathrm{P} f l g B$ promoter activity.

\section{DISCUSSION}

\section{Regulatory and General Proteolysis in Swimming Motility of $B$. subtilis}

In this work, we present a detailed analysis of the impact of Clp proteases on swimming motility in the model organism $B$. subtilis. We found that regulatory proteolysis of the transcription factors DegU and Spx by ClpCP and ClpXP, respectively, is an important mechanism to facilitate and control swimming motility. In the absence of these proteases, active DegU-P or Spx can accumulate and negatively regulate expression of the fla/che operon, resulting in low $\sigma^{\mathrm{D}}$ levels, lower expression of late flagellar genes and a loss of swimming motility. As already suggested for B. subtilis mutated in $c l p C$ (Rashid et al., 1996), these results may also explain the previously observed increased cell chaining in $c l p P$ and $c l p X$ mutants (Gerth et al., 1998;
Msadek et al., 1998), since autolysin genes, such as lytC and lytD, which are required for cell separation during division, are controlled by $\sigma^{\mathrm{D}}$.

Regulation of flagellar assembly is also strongly influenced by regulatory proteolysis in E. coli or Salmonella, where the stability of the master regulator FlhDC and the flagellar sigma factor FliA are controlled by ClpXP (Tomoyasu et al., 2003; Barembruch and Hengge, 2007; Kitagawa et al., 2011; Takaya et al., 2012).

A master regulator and activator of motility, such as FlhDC in E. coli has not been identified in B. subtilis and the two proteins with a described activator function, SwrA (Kearns and Losick, 2005) and DegU (Tsukahara and Ogura, 2008), are both dispensable for normal expression of the $\mathrm{fla} / \mathrm{che}$ operon for swimming motility in B. subtilis 168 strains. In most laboratory strains, such as $B$. subtilis 168 , SwrA is encoded as a cryptic gene and not synthesized. In less domesticated B. subtilis strains, such as the biofilm forming NCIB 3610 B. subtilis strain, SwrA, like a small number of other regulatory proteins, is present and active as an activator of swimming motility even enabling swarming motility (Kearns et al., 2004; McLoon et al., 2011). It was suggested that SwrA acts in conjunction and interacting with DegU-P, switching it from a repressor to an activator of the $\lg B$ promoter (Ogura and Tsukahara, 2012; Mordini et al., 2013). Interestingly, when we tested the effect of $c l p C$ and $c l p X$ mutations on a $B$. subtilis 168 strain complemented with $s w r A^{+}$ and $\operatorname{deg} Q^{+}$alleles or the B. subtilis NCIB 3610 strain encoding SwrA, we still observed a negative effect on swimming motility (Figure S12).

\section{ClpCP Influences Motility by Controlling the Activity of DegU P}

We demonstrate here that $\mathrm{ClpCP}$ regulates swimming motility not only by proteolysis of ComK, as previously reported (Liu 
A

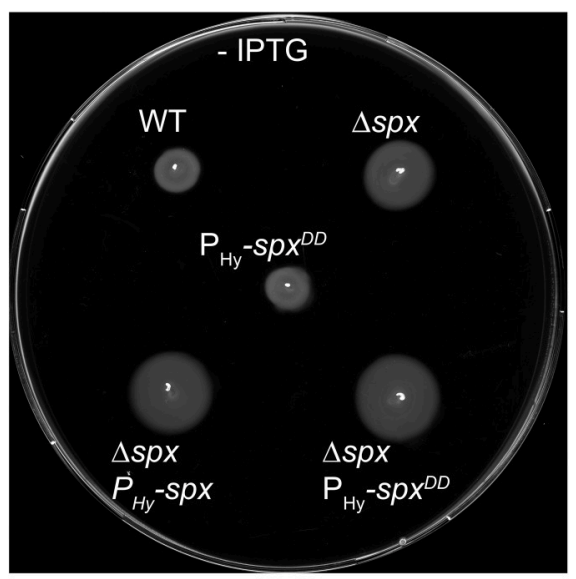

C

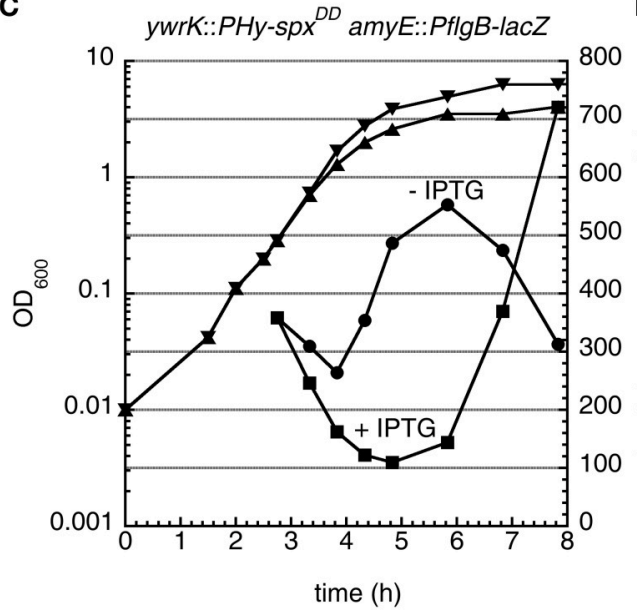

B

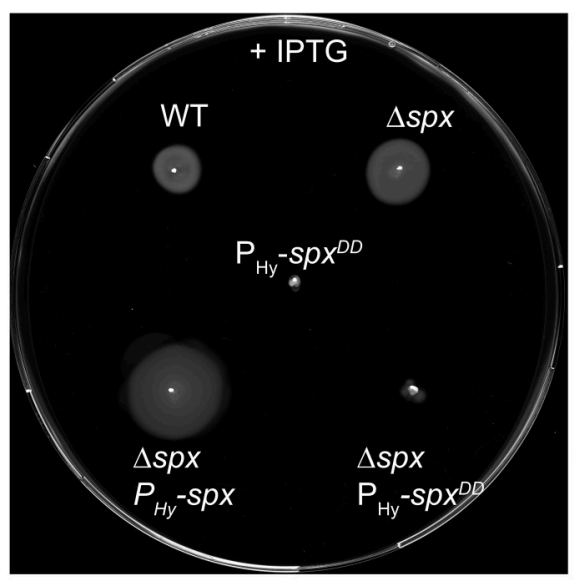

D

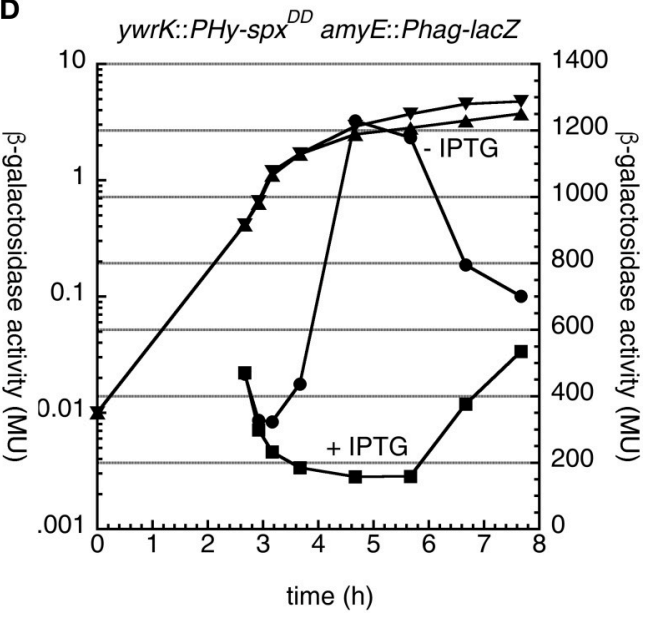

FIGURE 6 | Spx acts as a negative regulator of motility genes. (A) Motility assay of the indicated strains [wild type: WT, BNM111: $\Delta s p x, B N M 810: P_{H y}-S p x$ DD BNM350 ( $\left.\Delta s p x P_{H y}-s p x\right)$, BNM351 ( $\left.\Delta s p x P_{H y}-s p x{ }^{D D}\right)$ ]. Representative data from at least two experiments are shown. (B) Same as (A) using a swim agar plate containing $0.1 \mathrm{mM} I \mathrm{PTG}$ to induce $s p x^{\mathrm{DD}}$. (C) A B. subtilis strain carrying both a transcriptional flgB promoter lac $Z$ fusion at the $y w r K$ locus and an IPTG-inducible copy of $s p x^{\mathrm{DD}}$ at the amyE locus (BNM878) was grown in $\mathrm{LB}$ medium at $37^{\circ} \mathrm{C}$ and induced with $0.1 \mathrm{mM} I P T G$ in early exponential phase $\left(\mathrm{OD}_{600} 0.2-0.3\right)$. $\beta$-galactosidase activity was measured at the indicated time points. Circles: control without IPTG, squares: induced with 0.1 mM IPTG, inverted triangles: OD 600 , no IPTG; triangles: $\mathrm{OD}_{600}$, induced with $0.1 \mathrm{mM} I P T G$. (D) Same as (C) using a strain with a hag promoter lacZ fusion at the ywrK locus combined with an IPTG-inducible copy of $s p x^{\mathrm{DD}}$ at the amyE locus (BNM1001).

and Zuber, 1998), but also by controlling the activity or stability of DegU, which was recently identified as a proteolysis target of ClpCP (Ogura and Tsukahara, 2010). In accordance with these observations, we observed that both the $f l g B$ and hag promotors were down-regulated in the $\operatorname{clp} C$ mutant in a $\operatorname{deg} U$-dependent manner and the $\sigma^{\mathrm{D}}$ and Hag levels were strongly decreased, rendering the bacteria non-motile.

The function of DegU in motility development is complex and has been controversially discussed in the literature. Presumably, DegU can act both as an activator (Tsukahara and Ogura, 2008) and in its phosphorylated form as a repressor (Amati et al., 2004) of the $\lg B$ promoter. However, it has been demonstrated that $\operatorname{deg} U$ is required for swarming motility, whereas the gene is dispensable for swimming motility (Kobayashi, 2007; Verhamme et al., 2007). Our data are consistent with this hypothesis, as
degSU mutants were motile and producing Hag and the degSU mutation had only a minor effect on transcription of motility genes in our hands. Therefore, we conclude that under our conditions and in our strain background only the repressor function of DegU in its phosphorylated form is relevant for swimming motility and influenced by ClpC.

The $\operatorname{fgB}$ promoter features two DegU binding sites, one located upstream of the promoter (BR1) and one downstream in the $f \lg B$ coding region (BR2; Tsukahara and Ogura, 2008). The results presented here suggest that the downstream BR2 binding site is required for repression of the $f \lg B$ promoter by $\operatorname{DegU}$, since the longer lac $Z$ fusion that incorporates the BR2 site was down-regulated in the $c l p C$ mutant in a $\operatorname{deg} U$-dependent manner whereas the shorter fusion was not affected by the $c l p C$ mutation (Figure 2). These data are in accordance with those of Tsukahara 
A
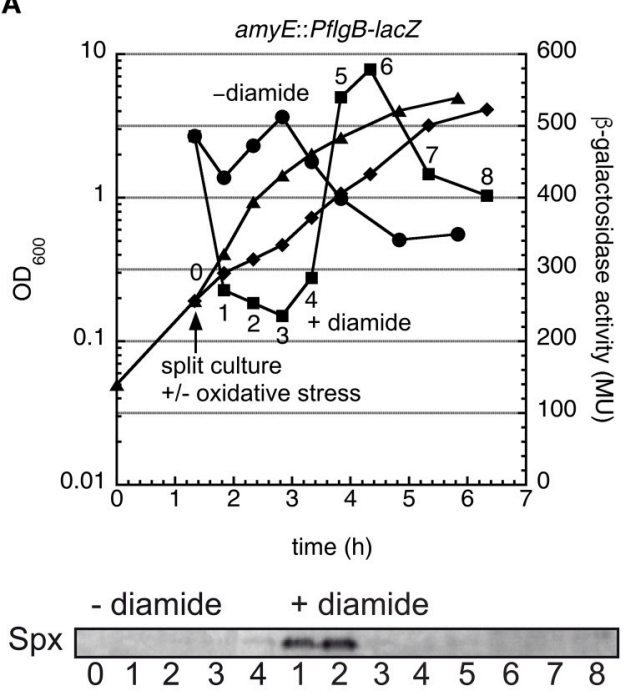

B
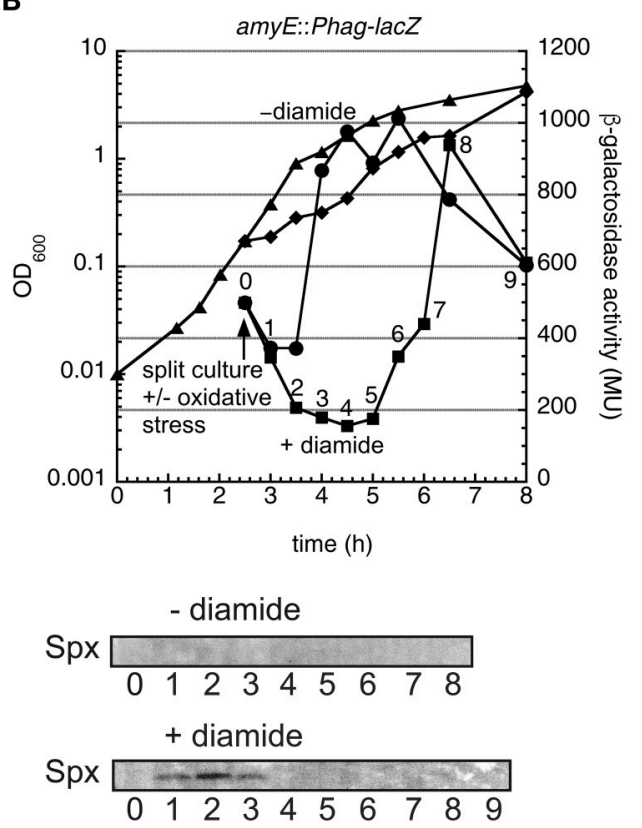

FIGURE 7 | Thiol oxidative stress results in transient down-regulation of motility genes in B. subtilis. (A) A growing culture of strain BNM301, carrying a transcriptional PflgB-lacZ fusion, was divided in early exponential phase and $1 \mathrm{mM}$ diamide was added to half of the culture to induce thiol oxidative stress. Samples were removed before addition of diamide and at the indicated time points and $\beta$-galactosidase activity was determined. Cell lysates of the same samples were analyzed by SDS-PAGE and Western blot against Spx (lower panel). Representative data from at least two experiments are shown. (B) Same as (A) for strain BNM328, carrying a transcriptional Phag-lacZ fusion.

et al., who reported that the BR2 binding site is required for $P f l g B$ repression in a $B$. subtilis strain carrying a $\operatorname{deg} U 32$ point mutant, which results in hyperphosphorylated DegU (Tsukahara and Ogura, 2008).

The long distance of the BR2 site from the core promoter suggests that DegU most probably does not repress $\operatorname{flg} B$ transcription by restricting access of RNA polymerase to the promoter. A similar mechanism was demonstrated for the repressor CodY, which binds to a site downstream of the $y b g E$ transcription start and negatively regulates transcription elongation by a roadblock mechanism, resulting in a short terminated mRNA fragment (Belitsky and Sonenshein, 2011).

Interestingly, it was reported that phosphorylated DegU acts as a negative regulator of motility by transcriptional activation of flgM (Hsueh et al., 2011). This effect provides an additional explanation for the observed down-regulation of the hag promoter, which is $\sigma^{\mathrm{D}}$-dependent and therefore negatively regulated by $\mathrm{FlgM}$, in the $c l p C$ mutant.

DegU has been described as a cellular rheostat that allows adequate expression of different groups of genes during transition to stationary phase to allow processes such as competence, biofilm formation, and motility. It was proposed that DegU degradation by ClpCP plays a part in fine-tuning of DegU auto-activation (Veening et al., 2008; Ogura and Tsukahara, 2010). The results presented here suggest that DegU activity and stability is also important for swimming motility. We assume that ClpCP-mediated inhibition and proteolysis ensures that active $\operatorname{DegU}$ concentration in the cell is kept below a threshold level, such that the $f \lg B$ promoter is de-repressed, but high enough to allow expression of other DegU-activated genes.

Most studies suggest that $\mathrm{DegU}$ acts as a $\mathrm{PflgB}$ repressor primarily in its phosphorylated form (Verhamme et al., 2007; Tsukahara and Ogura, 2008) and the experiments of Ogura and colleagues suggest that only phosphorylated DegU is targeted for ClpCP-mediated degradation (Ogura and Tsukahara, 2010). However, we observed in our strain and growth conditions some elevated DegU levels in vivo, but not to the extent observed before. Nevertheless, our experimental data are consistent with the role of $\mathrm{DegU} \sim \mathrm{P}$ as a repressor of motility, which is specifically inhibited by $\mathrm{ClpC}$. It should be noted that $\mathrm{ClpC}$ alone could be sufficient to repress DegU-P activity by unfolding DegU-P without targeting it to ClpP. It would be very interesting to explore by what mechanism phosphorylated DegU is recognized by $\mathrm{ClpC}$ and under what conditions it is targeted for degradation to ClpCP.

\section{Regulatory Proteolysis of Spx by ClpXP Influences Swimming Motility}

The second principal finding of this paper is the observation that swimming motility is inhibited in a $c p X$ mutant via the stabilization of the ClpXP substrate Spx, which acts as a negative regulator of motility. We have demonstrated that an $s p x$ mutant suppresses the decreased swimming motility observed in a $\operatorname{clpX}$ mutant (Figure 4) and that raised levels of 
$\mathrm{Spx}^{\mathrm{DD}}$ in a $\operatorname{clp} \mathrm{X}^{+}$background inhibit motility (Figure 5). Our results suggest that $\mathrm{Spx}$ inhibits motility at the level of the flgB promoter (Figures 5, 6) and can in addition also influence the hag promoter (Figure S3). Furthermore, we could demonstrate that motility gene expression is transiently inhibited during thiol oxidative stress, which activates and stabilizes Spx (Figure 7).

Spx-mediated down-regulation of motility provides a connection between motility and a stress response pathway. The oxidative stress response requires a restructuring of the proteome redox enzymes and chaperones (Zuber, 2009). Likewise, swimming motility requires a substantial effort both for production of the flagellar proteins and their assembly (Chevance and Hughes, 2008). Exerting both programs at the same time could be detrimental for these cells. Our observations suggest that upon oxidative stress or induction of $\mathrm{Spx}^{\mathrm{DD}}$ the cells give priority to the stress response. However, they can resume motility development after oxidative stress has been alleviated (Figures 6, 7).

Importantly, this does not necessarily require that individual cells are non-motile during the stress response, since only flagellar gene expression is down-regulated. Already existing flagella could continue to function, which might even be an advantage for cells, enabling them to escape from the source of the stress by chemotaxis and swimming motility.

\section{Possible Mechanisms of Motility Regulation by Spx}

Spx is a transcription factor, which interacts with the alpha subunit of RNA polymerase and enhances polymerase binding to certain promoters (Reyes and Zuber, 2008; Nakano et al., 2010). This mechanism is shared by a number of transcriptional activators, including response regulators such as ComA (Nakano et al., 2003b). According to the interference model, Spx does not directly act as a repressor, but restricts access of other transcription factors to the RNA polymerase alpha subunit when present at high concentrations. By this mechanism for example are competence genes repressed in the presence of Spx, because phosphorylated ComA can no longer bind to RNA polymerase (Nakano et al., 2003b). As already mentioned, an activator of transcription of the $f l g B$ promoter in $B$. subtilis 168 is not known, therefore it is very unlikely that Spx could act as a repressor of $\mathrm{P} f \lg B$ by interfering with an activator.

It was recently observed that Spx can activate the transcription of degSU (Shiwa et al., 2015), which could potentially effect the regulation of motility. However, we observed that a deletion of degSU did not interfere with the Spx mediated inhibition of motility (Figure S6) and no elevated DegU levels were observed in a $c l p X$ mutant (Figure 2G). However, the implications of raised levels of DegU and DegS on regulation of motility should be investigated in more detail.

DNA binding of Spx in the absence of RNA polymerase alpha CTD has never been observed and we have shown that Spx does not bind to the $\lg B$ promoter fragment in vitro (Figure S11). An indirect regulation of motility by Spx is also supported by a study, in which the Spx regulon was analyzed by tiling arrays and a genome wide characterization of Spx binding sites was accomplished. Spx-dependent repression of a number of motility and chemotaxis genes was observed in these experiments, but since no relevant Spx binding sites e.g., near the $\operatorname{lgB}$ and hag promoter were identified, this was considered an indirect Spxmediated effect (Rochat et al., 2012). This suggests that Spx rather indirectly influences the $\mathrm{flgB}$ promoter and $\mathrm{fla} /$ che expression, for example by transcriptional activation of a repressor or other not yet identified intracellular signal transduction mechanisms. More experiments will be necessary to understand and elucidate the mechanism by which Spx influences motility via the $f l g B$ and hag promoters in B. subtilis.

In summary, we have uncovered two additional pathways, by which regulatory proteolysis affects swimming motility in $B$. subtilis. We could demonstrate that ClpCP contributes to motility development by controlling the stability of the response regulator DegU, which can act as a repressor of the fla/che operon. In turn, ClpXP facilitates swimming motility by proteolysis of its substrate Spx. We could show that the oxidative stress regulator Spx acts as a negative regulator of motility on the $\lg B$ promoter and the hag promoter. The additionally observed Spx-mediated repression of hag might also be facilitated by a yet unknown posttranscriptional process. Importantly, the influence of Spx on motility could also be observed in wild type cells during oxidative stress and can therefore be considered as a biologically relevant stress response mechanism.

These results highlight the complex involvement of controlled proteolysis in the regulation of motility and its intricate connections to stress response pathways such as the Spx controlled thiol stress response (Zuber, 2004, 2009) or heat shock response (Runde et al., 2014) and the various processes (such as e.g., biofilm formation) controlled by the master regulator DegU (Murray et al., 2009).

\section{AUTHOR CONTRIBUTIONS}

NM designed research, performed experiments, analyzed results, and wrote the paper. $\mathrm{JH}$ designed research, performed experiments and analyzed data. HS designed research, performed experiments and analyzed data KT designed research, analyzed results, and wrote the paper.

\section{FUNDING}

We acknowledge support by Deutsche Forschungsgemainschaft (Tu106/6, Tu106/7) and Open Access Publishing Fund of Leibniz Universität Hannover.

\section{ACKNOWLEDGMENTS}

We want to thank Peter Zuber (University of Oregon), Dan Kearns (Indiana University), Ulf Gerth and Michael Hecker (University of Greifswald), Linc Sonenshein (Tufts University), Nicola Stanley-Wall (University of Dundee), Claes von Wachenfeldt (Lund University), and John Helmann (Cornell University) for the gift of antibodies, strains, or plasmids. We 
are grateful to Ilka Slosarek, Sabine Kretschmer (FU Berlin), and Armgard Janczikowski (Leibniz Universität Hannover) for excellent technical assistance. In addition, we thank Alex Elsholz (MPI Marburg) and Hendrik Osadnik (UC San Francisco) for critical reading of the manuscript.

\section{REFERENCES}

Ababneh, Q. O., and Herman, J. K. (2015). CodY regulates SigD levels and activity by binding to three sites in the fla/che operon. J. Bacteriol. 197, 2999-3006. doi: 10.1128/JB.00288-15

Amati, G., Bisicchia, P., and Galizzi, A. (2004). DegU-P represses expression of the motility fla-che operon in Bacillus subtilis. J. Bacteriol. 186, 6003-6014. doi: 10.1128/JB.186.18.6003-6014.2004

Anagnostopoulos, C., and Spizizen, J. (1961). Requirements for Transformation in Bacillus subtilis. J. Bacteriol. 81, 741-746.

Arnaud, M., Chastanet, A., and Débarbouillé, M. (2004). New vector for efficient allelic replacement in naturally nontransformable, low-GC-content, gram-positive bacteria. Appl. Environ. Microbiol. 70, 6887-6891. doi: 10.1128/AEM.70.11.6887-6891.2004

Barembruch, C., and Hengge, R. (2007). Cellular levels and activity of the flagellar sigma factor FliA of Escherichia coli are controlled by FlgM-modulated proteolysis. Mol. Microbiol. 65, 76-89. doi: 10.1111/j.1365-2958.2007.05770.x

Battesti, A., and Gottesman, S. (2013). Roles of adaptor proteins in regulation of bacterial proteolysis. Curr. Opin. Microbiol. 16, 140-147. doi: 10.1016/j.mib.2013.01.002

Belitsky, B. R., and Sonenshein, A. L. (2011). Roadblock repression of transcription by Bacillus subtilis CodY. J. Mol. Biol. 411, 729-743. doi: 10.1016/j.jmb.2011.06.012

Belitsky, B. R., and Sonenshein, A. L. (2013). Genome-wide identification of Bacillus subtilis CodY-binding sites at single-nucleotide resolution. Proc. Natl. Acad. Sci. U.S.A. 110, 7026-7031. doi: 10.1073/pnas.1300428110

Bergara, F., Ibarra, C., Iwamasa, J., Patarroyo, J. C., Aguilera, R., and Márquez-Magaña, L. M. (2003). CodY is a nutritional repressor of flagellar gene expression in Bacillus subtilis. J. Bacteriol. 185, 3118-3126. doi: 10.1128/JB.185.10.3118-3126.2003

Bertero, M. G., Gonzales, B., Tarricone, C., Ceciliani, F., and Galizzi, A. (1999). Overproduction and characterization of the Bacillus subtilis antisigma factor FlgM. J. Biol. Chem. 274, 12103-12107. doi: 10.1074/jbc.274.1 7.12103

Blair, K. M., Turner, L., Winkelman, J. T., Berg, H. C., and Kearns, D. B. (2008). A molecular clutch disables flagella in the Bacillus subtilis biofilm. Science 320, 1636-1638. doi: 10.1126/science. 1157877

Bradford, M. M. (1976). A rapid and sensitive method for the quantitation of microgram quantities of protein utilizing the principle of protein-dye binding. Anal. Biochem. 72, 248-254. doi: 10.1016/0003-2697(76)90527-3

Calvio, C., Osera, C., Amati, G., and Galizzi, A. (2008). Autoregulation of swrAA and motility in Bacillus subtilis. J. Bacteriol. 190, 5720-5728. doi: 10.1128/JB.00455-08

Calvo, R. A., and Kearns, D. B. (2015). FlgM is secreted by the flagellar export apparatus in Bacillus subtilis. J. Bacteriol. 197, 81-91. doi: 10.1128/JB.02324-14

Camp, A. H., and Losick, R. (2009). A feeding tube model for activation of a cellspecific transcription factor during sporulation in Bacillus subtilis. Genes Dev. 23, 1014-1024. doi: 10.1101/gad.1781709

Caramori, T., Barilla, D., Nessi, C., Sacchi, L., and Galizzi, A. (1996). Role of FlgM in sigma D-dependent gene expression in Bacillus subtilis. J. Bacteriol. 178, 3113-3118.

Chai, Y., Kolter, R., and Losick, R. (2010). Reversal of an epigenetic switch governing cell chaining in Bacillus subtilis by protein instability. Mol. Microbiol. 78, 218-229. doi: 10.1111/j.1365-2958.2010.07335.x

Chevance, F. F. V., and Hughes, K. T. (2008). Coordinating assembly of a bacterial macromolecular machine. Nat. Rev. Microbiol. 6, 455-465. doi: $10.1038 /$ nrmicro 1887

\section{SUPPLEMENTARY MATERIAL}

The Supplementary Material for this article can be found online at: http://journal.frontiersin.org/article/10.3389/fmicb. 2016.00315

Cozy, L. M., and Kearns, D. B. (2010). Gene position in a long operon governs motility development in Bacillus subtilis. Mol. Microbiol. 76, 273-285. doi: 10.1111/j.1365-2958.2010.07112.x

Derré, I., Rapoport, G., and Msadek, T. (1999). CtsR, a novel regulator of stress and heat shock response, controls $c l p$ and molecular chaperone gene expression in gram-positive bacteria. Mol. Microbiol. 31, 117-131. doi: 10.1046/j.13652958.1999.01152.x

Engman, J., and von Wachenfeldt, C. (2015). Regulated protein aggregation: a mechanism to control the activity of the ClpXP adaptor protein YjbH. Mol. Microbiol. 95, 51-63. doi: 10.1111/mmi.12842

Fredrick, K., and Helmann, J. D. (1996). FlgM is a primary regulator of sigmaD activity, and its absence restores motility to a $\operatorname{sinR}$ mutant. J. Bacteriol. 178, 7010-7013.

Garg, S. K., Kommineni, S., Henslee, L., Zhang, Y., and Zuber, P. (2009). The YjbH protein of Bacillus subtilis enhances ClpXP-catalyzed proteolysis of Spx. J. Bacteriol. 191, 1268-1277. doi: 10.1128/JB.01289-08

Gerth, U., Krüger, E., Derré, I., Msadek, T., and Hecker, M. (1998). Stress induction of the Bacillus subtilis clpP gene encoding a homologue of the proteolytic component of the Clp protease and the involvement of ClpP and ClpX in stress tolerance. Mol. Microbiol. 28, 787-802. doi: 10.1046/j.1365-2958.1998.00840.x

Helmann, J. D., Wu, M. F., Kobel, P. A., Gamo, F. J., Wilson, M., Morshedi, M. M., et al. (2001). Global transcriptional response of Bacillus subtilis to heat shock. J. Bacteriol. 183, 7318-7328. doi: 10.1128/JB.183.24.7318-7328.2001

Hsueh, Y.-H., Cozy, L. M., Sham, L.-T., Calvo, R. A., Gutu, A. D., Winkler, M. E., et al. (2011). DegU-phosphate activates expression of the anti-sigma factor FlgM in Bacillus subtilis. Mol. Microbiol. 81, 1092-1108. doi: 10.1111/j.13652958.2011.07755.x

Kearns, D. B., Chu, F., Rudner, R., and Losick, R. (2004). Genes governing swarming in Bacillus subtilis and evidence for a phase variation mechanism controlling surface motility. Mol. Microbiol. 52, 357-369. doi: 10.1111/j.13652958.2004.03996.x

Kearns, D. B., and Losick, R. (2005). Cell population heterogeneity during growth of Bacillus subtilis. Genes Dev. 19, 3083-3094. doi: 10.1101/gad.1373905

Kirstein, J., Dougan, D. A., Gerth, U., Hecker, M., and Turgay, K. (2007). The tyrosine kinase McsB is a regulated adaptor protein for ClpCP. EMBO J. 26, 2061-2070. doi: 10.1038/sj.emboj.7601655

Kirstein, J., Molière, N., Dougan, D. A., and Turgay, K. (2009). Adapting the machine: adaptor proteins for Hsp100/Clp and AAA+ proteases. Nat. Rev. Microbiol. 7, 589-599. doi: 10.1038/nrmicro 2185

Kitagawa, R., Takaya, A., and Yamamoto, T. (2011). Dual regulatory pathways of flagellar gene expression by ClpXP protease in enterohaemorrhagic Escherichia coli. Microbiology 157, 3094-3103. doi: 10.1099/mic.0.0 51151-0

Kobayashi, K. (2007). Gradual activation of the response regulator DegU controls serial expression of genes for flagellum formation and biofilm formation in Bacillus subtilis. Mol. Microbiol. 66, 395-409. doi: 10.1111/j.13652958.2007.05923.x

Krüger, E., Witt, E., Ohlmeier, S., Hanschke, R., and Hecker, M. (2000). The Clp proteases of Bacillus subtilis are directly involved in degradation of misfolded proteins. J. Bacteriol. 182, 3259-3265. doi: 10.1128/JB.182.11.3259-326 5.2000

Krüger, E., Zühlke, D., Witt, E., Ludwig, H., and Hecker, M. (2001). Clp-mediated proteolysis in Gram-positive bacteria is autoregulated by the stability of a repressor. EMBO J. 20, 852-863. doi: 10.1093/emboj/20.4.852

Leelakriangsak, M., Kobayashi, K., and Zuber, P. (2007). Dual negative control of $s p x$ transcription initiation from the P3 promoter by repressors PerR 
and YodB in Bacillus subtilis. J. Bacteriol. 189, 1736-1744. doi: 10.1128/JB. 01520-06

Liu, J., and Zuber, P. (1998). A molecular switch controlling competence and motility: competence regulatory factors ComS, MecA, and ComK control sigmaD-dependent gene expression in Bacillus subtilis. J. Bacteriol. 180, 4243-4251.

Márquez, L. M., Helmann, J. D., Ferrari, E., Parker, H. M., Ordal, G. W., and Chamberlin, M. J. (1990). Studies of sigma D-dependent functions in Bacillus subtilis. J. Bacteriol. 172, 3435-3443.

Márquez-Magaña, L. M., and Chamberlin, M. J. (1994). Characterization of the sigD transcription unit of Bacillus subtilis. J. Bacteriol. 176, 2427-2434.

McLoon, A. L., Guttenplan, S. B., Kearns, D. B., Kolter, R., and Losick, R. (2011). Tracing the domestication of a biofilmforming bacterium. J. Bacteriol. 193, 2027-2034. doi: 10.1128/JB.0 1542-10

Miethke, M., Hecker, M., and Gerth, U. (2006). Involvement of Bacillus subtilis $\mathrm{ClpE}$ in CtsR degradation and protein quality control. J. Bacteriol. 188, 4610-4619. doi: 10.1128/JB.00287-06

Mirel, D. B., and Chamberlin, M. J. (1989). The Bacillus subtilis flagellin gene ( hag) is transcribed by the sigma 28 form of RNA polymerase. J. Bacteriol. 171, 3095-3101.

Mirel, D. B., Lauer, P., and Chamberlin, M. J. (1994). Identification of flagellar synthesis regulatory and structural genes in a Sigma D-dependent operon of Bacillus subtilis. J. Bacteriol. 176, 4492-4500.

Mordini, S., Osera, C., Marini, S., Scavone, F., Bellazzi, R., Galizzi, A., et al. (2013). The role of SwrA, DegU and $\mathrm{P}(\mathrm{D} 3)$ in fla/che expression in B. subtilis. PLoS ONE 8:e85065. doi: 10.1371/journal.pone.0 085065

Msadek, T., Dartois, V., Kunst, F., Herbaud, M. L., Denizot, F., and Rapoport, G. (1998). ClpP of Bacillus subtilis is required for competence development, motility, degradative enzyme synthesis, growth at high temperature and sporulation. Mol. Microbiol. 27, 899-914. doi: 10.1046/j.13652958.1998.00735.x

Mukherjee, S., and Kearns, D. B. (2014). The structure and regulation of flagella in Bacillus subtilis. Annu. Rev. Genet. 48, 319-340. doi: 10.1146/annurev-genet120213-092406

Murray, E. J., Kiley, T. B., and Stanley-Wall, N. R. (2009). A pivotal role for the response regulator DegU in controlling multicellular behaviour. Microbiology 155, 1-8. doi: 10.1099/mic.0.023903-0

Nakano, M. M., Hajarizadeh, F., Zhu, Y., and Zuber, P. (2001). Lossof-function mutations in $y j b D$ result in ClpX- and ClpP-independent competence development of Bacillus subtilis. Mol. Microbiol. 42, 383-394. doi: 10.1046/j.1365-2958.2001.02639.x

Nakano, M. M., Lin, A., Zuber, C. S., Newberry, K. J., Brennan, R. G., and Zuber, P. (2010). Promoter recognition by a complex of Spx and the Cterminal domain of the RNA polymerase alpha subunit. PLOS ONE 5:e8664. doi: 10.1371/journal.pone.0008664

Nakano, M. M., Nakano, S., and Zuber, P. (2002). Spx (YjbD), a negative effector of competence in Bacillus subtilis, enhances ClpC-MecA-ComK interaction. Mol. Microbiol. 44, 1341-1349. doi: 10.1046/j.1365-2958.2002. 02963.x

Nakano, S., Küster-Schöck, E., Grossman, A. D., and Zuber, P. (2003a). Spxdependent global transcriptional control is induced by thiol-specific oxidative stress in Bacillus subtilis. Proc. Natl. Acad. Sci. U.S.A. 100, 13603-13608. doi: 10.1073/pnas.2235180100

Nakano, S., Nakano, M. M., Zhang, Y., Leelakriangsak, M., and Zuber, P. (2003b). A regulatory protein that interferes with activator-stimulated transcription in bacteria. Proc. Natl. Acad. Sci. U.S.A. 100, 4233-4238. doi: 10.1073/pnas.0637648100

Nakano, S., Zheng, G., Nakano, M. M., and Zuber, P. (2002). Multiple pathways of Spx (YjbD) proteolysis in Bacillus subtilis. J. Bacteriol. 184, 3664-3670. doi: 10.1128/JB.184.13.3664-3670.2002

Newberry, K. J., Nakano, S., Zuber, P., and Brennan, R. G. (2005). Crystal structure of the Bacillus subtilis anti-alpha, global transcriptional regulator, Spx, in complex with the alpha C-terminal domain of RNA polymerase. Proc. Natl. Acad. Sci. U.S.A. 102, 15839-15844. doi: 10.1073/pnas.0506 592102
Ogura, M., and Tsukahara, K. (2010). Autoregulation of the Bacillus subtilis response regulator gene $\operatorname{deg} U$ is coupled with the proteolysis of DegU-P by ClpCP. Mol. Microbiol. 75, 1244-1259. doi: 10.1111/j.1365-2958.2010.07047.x

Ogura, M., and Tsukahara, K. (2012). SwrA regulates assembly of Bacillus subtilis DegU via its interaction with N-terminal domain of DegU. J. Biochem. 151, 643-655. doi: 10.1093/jb/mvs036

Pan, Q., Garsin, D. A., and Losick, R. (2001). Self-reinforcing activation of a cell-specific transcription factor by proteolysis of an anti-sigma factor in B. subtilis. Mol. Cell 8, 873-883. doi: 10.1016/S1097-2765(01) 00362-8

Rashid, M. H., Tamakoshi, A., and Sekiguchi, J. (1996). Effects of $m e c A$ and $m e c B$ $(c l p C)$ mutations on expression of $s i g D$, which encodes an alternative sigma factor, and autolysin operons and on flagellin synthesis in Bacillus subtilis. J. Bacteriol. 178, 4861-4869.

Reyes, D. Y., and Zuber, P. (2008). Activation of transcription initiation by Spx: formation of transcription complex and identification of a Cis-acting element required for transcriptional activation. Mol. Microbiol. 69, 765-779. doi: 10.1111/j.1365-2958.2008. 06330.x

Rochat, T., Nicolas, P., Delumeau, O., Rabatinová, A., Korelusová, J., Leduc, A., et al. (2012). Genome-wide identification of genes directly regulated by the pleiotropic transcription factor Spx in Bacillus subtilis. Nucleic Acids Res. 40, 9571-9583. doi: 10.1093/nar/gks755

Runde, S., Molière, N., Heinz, A., Maisonneuve, E., Janczikowski, A., Elsholz, A. K. W., et al. (2014). The role of thiol oxidative stress response in heat-induced protein aggregate formation during thermotolerance in Bacillus subtilis. Mol. Microbiol. 91, 1036-1052. doi: 10.1111/mmi. 12521

Sambrook, J., Russell, D. W., and Cold Spring Harbor Laboratory (2001). Molecular Cloning: A Laboratory Manual, 3rd Edn. Cold Spring Harbor, NY: Cold Spring Harbor Laboratory.

Sauer, R. T., and Baker, T. A. (2011). AAA+ proteases: ATP-fueled machines of protein destruction. Annu. Rev. Biochem. 80, 587-612. doi: 10.1146/annurevbiochem-060408-172623

Schlothauer, T., Mogk, A., Dougan, D. A., Bukau, B., and Turgay, K. (2003). MecA, an adaptor protein necessary for ClpC chaperone activity. Proc. Natl. Acad. Sci. U.S.A. 100, 2306-2311. doi: 10.1073/pnas.05357 17100

Shiwa, Y., Yoshikawa, H., Tanaka, T., and Ogura, M. (2015). Bacillus subtilis degSU operon is regulated by the ClpXP-Spx regulated proteolysis system. J. Biochem. 157, 321-330. doi: 10.1093/jb/mvu076

Takaya, A., Erhardt, M., Karata, K., Winterberg, K., Yamamoto, T., and Hughes, K. T. (2012). YdiV: a dual function protein that targets FlhDC for ClpXP-dependent degradation by promoting release of DNA-bound FlhDC complex. Mol. Microbiol. 83, 1268-1284. doi: 10.1111/j.1365-2958.2012. 08007.x

Tomoyasu, T., Takaya, A., Isogai, E., and Yamamoto, T. (2003). Turnover of FlhD and FlhC, master regulator proteins for Salmonella flagellum biogenesis, by the ATP-dependent ClpXP protease. Mol. Microbiol. 48, 443-452. doi: 10.1046/j.1365-2958.2003.03437.x

Tsukahara, K., and Ogura, M. (2008). Promoter selectivity of the Bacillus subtilis response regulator DegU, a positive regulator of the fla/che operon and $s a c B$. BMC Microbiol. 8:8. doi: 10.1186/1471-2180-8-8

Turgay, K., Hahn, J., Burghoorn, J., and Dubnau, D. (1998). Competence in Bacillus subtilis is controlled by regulated proteolysis of a transcription factor. EMBO J. 17, 6730-6738. doi: 10.1093/emboj/17.22.6730

Veening, J.-W., Igoshin, O. A., Eijlander, R. T., Nijland, R., Hamoen, L. W., and Kuipers, O. P. (2008). Transient heterogeneity in extracellular protease production by Bacillus subtilis. Mol. Syst. Biol. 4, 184. doi: 10.1038/msb. 2008.18

Verhamme, D. T., Kiley, T. B., and Stanley-Wall, N. R. (2007). DegU coordinates multicellular behaviour exhibited by Bacillus subtilis. Mol. Microbiol. 65, 554-568. doi: 10.1111/j.1365-2958.2007.05810.x

Wach, A. (1996). PCR-synthesis of marker cassettes with long flanking homology regions for gene disruptions in S. cerevisiae. Yeast 12, 259-265.

Zhang, Y., Nakano, S., Choi, S.-Y., and Zuber, P. (2006). Mutational analysis of the Bacillus subtilis RNA polymerase alpha C-terminal domain supports the 
interference model of Spx-dependent repression. J. Bacteriol. 188, 4300-4311. doi: 10.1128/JB.00220-06

Zhang, Y., and Zuber, P. (2007). Requirement of the zinc-binding domain of ClpX for Spx proteolysis in Bacillus subtilis and effects of disulfide stress on ClpXP activity. J. Bacteriol. 189, 7669-7680. doi: 10.1128/JB.00745-07

Zuber, P. (2004). Spx-RNA polymerase interaction and global transcriptional control during oxidative stress. J. Bacteriol. 186, 1911-1918. doi: 10.1128/JB.186.7.1911-1918.2004

Zuber, P. (2009). Management of oxidative stress in Bacillus. Annu. Rev. Microbiol. 63, 575-597. doi: 10.1146/annurev.micro.091208.073241
Conflict of Interest Statement: The authors declare that the research was conducted in the absence of any commercial or financial relationships that could be construed as a potential conflict of interest.

Copyright $\odot 2016$ Molière, Hoßmann, Schäfer and Turgay. This is an open-access article distributed under the terms of the Creative Commons Attribution License (CC $B Y)$. The use, distribution or reproduction in other forums is permitted, provided the original author(s) or licensor are credited and that the original publication in this journal is cited, in accordance with accepted academic practice. No use, distribution or reproduction is permitted which does not comply with these terms. 